University of Louisville

ThinkIR: The University of Louisville's Institutional Repository

Electronic Theses and Dissertations

8-2015

\title{
The role of self-discrepancies in American Jewish identities on mental and spiritual well-being.
}

Jason Goldstein

University of Louisville

Follow this and additional works at: https://ir.library.louisville.edu/etd

Part of the Student Counseling and Personnel Services Commons

\section{Recommended Citation}

Goldstein, Jason, "The role of self-discrepancies in American Jewish identities on mental and spiritual well-being." (2015). Electronic Theses and Dissertations. Paper 2236.

https://doi.org/10.18297/etd/2236

This Doctoral Dissertation is brought to you for free and open access by ThinkIR: The University of Louisville's Institutional Repository. It has been accepted for inclusion in Electronic Theses and Dissertations by an authorized administrator of ThinkIR: The University of Louisville's Institutional Repository. This title appears here courtesy of the author, who has retained all other copyrights. For more information, please contact thinkir@louisville.edu. 


\title{
THE ROLE OF SELF-DISCREPANCIES IN AMERICAN JEWISH IDENTITIES ON MENTAL AND SPIRITUAL WELL-BEING
}

\author{
By \\ Jason Goldstein \\ B.S. University of Florida, 2009 \\ M.Ed. University of Louisville, 2012
}

\begin{abstract}
A Dissertation Submitted to the Faculty of the College of Education and Human Development of the University of Louisville in Partial Fulfillment of the Requirements for the Degree of
\end{abstract}

Doctor of Philosophy in Counseling and Personnel Services

Department of Counseling Psychology

University of Louisville

Louisville, Kentucky

August 2015 



\title{
THE ROLE OF SELF-DISCREPANCIES IN AMERICAN JEWISH IDENTITY ON MENTAL AND SPIRITUAL WELL-BEING
}

\author{
By \\ Jason Goldstein \\ B.S., University of Florida, 2009 \\ M.Ed., University of Louisville, 2012 \\ A Dissertation Approved on
}

July 17,2015

by the following Dissertation Committee:

Dissertation Chair

Mark M. Leach, Ph.D.

Committee Member

Jesse Owen, Ph.D.

Committee Member

Patrick Pössel, Dr. rer. soc.

\section{Committee Member \\ Brad Shuck, Ph.D.}




\section{DEDICATION}

This dissertation is dedicated to my family and my childhood Jewish community for

giving me life (literally and figuratively), for sustaining me, and for enabling me to reach this goal and this profession. L'Chaim! 


\section{ACKNOWLEDGEMENTS}

This dissertation was made possible by the direction, patience, and alwaysinteresting brainstorming sessions from my advisor, Dr. Mark Leach. His never-ending prodding and support helped this clinically-focused supervisee complete this dissertation that maintained and expanded both our interests in the intersection of spirituality and psychology (as long as it did not involve religious coping). Furthermore, I would like to thank my entire dissertation committee—Dr. Jesse Owen, Dr. Patrick Pössel, and Dr. Brad Shuck - for your insights, suggestions, and interest in this topic that has allowed me to extend my passion for Judaism into my empirical explorations. I owe words of gratitude to all of my faculty, practicum, and internship supervisors for providing the perfect balance of challenge and support for me to develop into the clinician I am today. Lastly, I would like to acknowledge the original and adopted phenomenal geniuses of the University of Louisville Counseling Psychology program for helping to build a community of caring and exploration that made my graduate studies a resounding joy. 


\section{ABSTRACT \\ THE ROLE OF SELF-DISCREPANCIES IN AMERICAN JEWISH IDENTITY ON MENTAL AND SPIRITUAL WELL-BEING \\ Jason Goldstein}

July 17, 2015

Contemporary American Jews individually define their own Jewish identity developed through both religious and cultural foundations (Cohen \& Eisen, 2000), yet there is limited empirical research on the experience of Jewish identity and its impact on mental and spiritual well-being. Beyond denominational affiliation, each Jewish individual builds a Jewish identity based on personally desired levels of participation in one's Jewish community (Ideal Jewish Identity) as well as perceived expectations and obligations of a Jewish life (Ought Jewish Identity), although the internalized desires and expectations may not be fulfilled. Building upon the foundation established by Rogers (1954) and Higgins (1986), the perception of not being a "good enough Jew" can be conceptualized as self-discrepancies in one's Jewish identity and may result in negative psychological and spiritual consequences. A large sample $(\mathrm{N}=829)$ of Americans selfidentifying as Jewish participated in an online survey which included completion of the American Jewish Identity Scale (Friedlander et al., 2010) from two different perspectives to calculate discrepancies. Results showed that Jews identified both Ideal and Ought Jewish self-discrepancies, religious Ideal and cultural Ought discrepancies demonstrated small positive effects on the presence of anxiety and depressive symptoms, and religious 
discrepancies positively impacted religious well-being. The perception of failing to meet the idiosyncratically defined desires and expectations of one's Jewish identity, particularly concerning level of involvement in one's cultural community, appears to reduce mental well-being while also stimulating motivation to increase religious participation. Exploration of Jewish identity, whether within empirical studies or affirmative therapy for Jewish individuals, would benefit from expanding the scope of understanding beyond denominational affiliation to include self-discrepancies in one's religious and cultural identities. 


\section{TABLE OF CONTENTS}

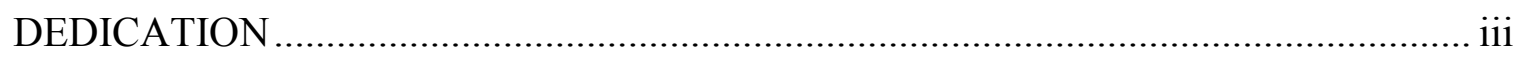

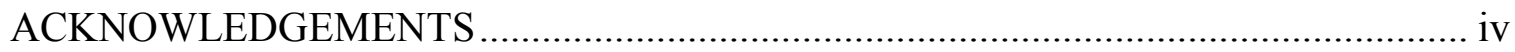

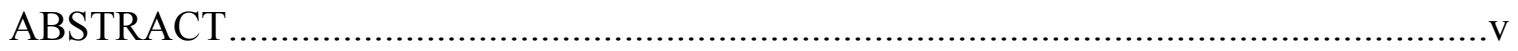

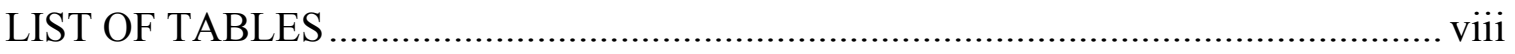

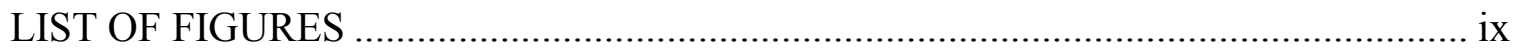

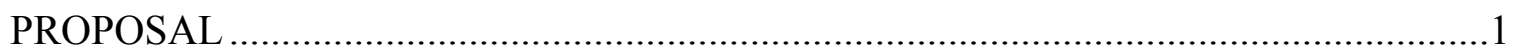

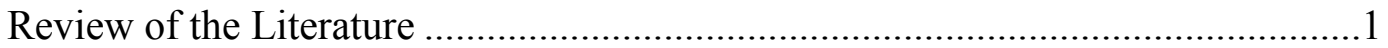

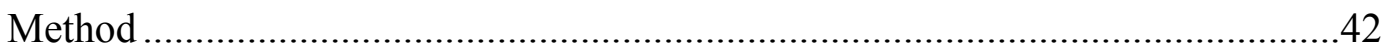

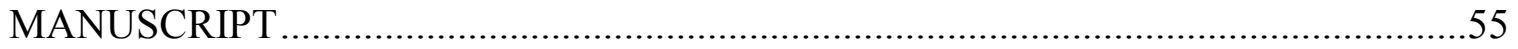

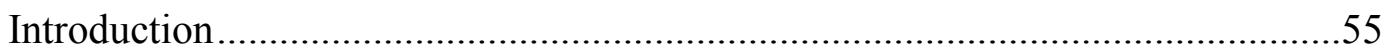

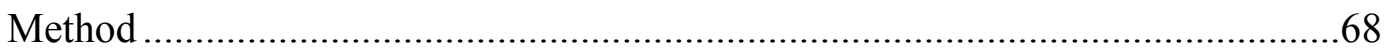

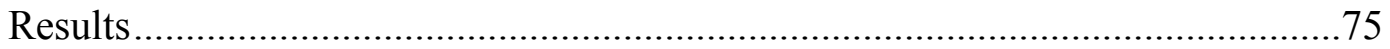

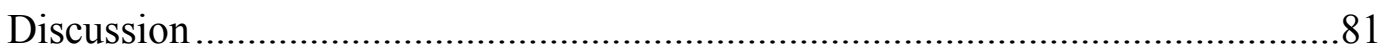

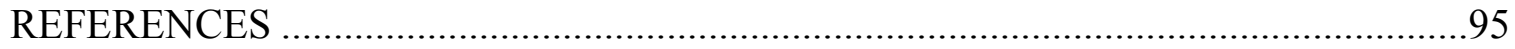

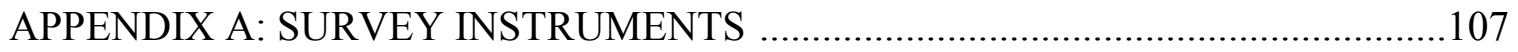

APPENDIX B: TABLES AND FIGURES............................................................111

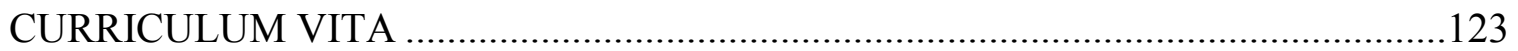




\section{LIST OF TABLES}

1. Intercorrelations of the Major Variables ........................................................ 111

2. Actual, Ideal, and Ought Jewish Identity Means and Standard Deviations.................112

3. Actual-Ideal and Actual-Ought Discrepancies Means, SDs, and Effect Sizes ............113

4. Interaction Effects with Moderation Variables on Mental Well-Being .......................114

5. Interaction Effects with Moderation Variables on Spiritual Well-Being ..................115 


\section{LIST OF FIGURES}

1. Model of Jewish Self-Discrepancies on Mental Well-Being ..................................116

2. Model of Jewish Self-Discrepancies on Spiritual Well-being .................................117

3. Results of Ideal Jewish Self-Discrepancies on Mental Well-Being ..........................118

4. Results of Ought Jewish Self-Discrepancies on Mental Well-Being .......................119

5. Results of Ideal Jewish Self-Discrepancies on Spiritual Well-Being ........................120

6. Results of Ought Jewish Self-Discrepancies on Spiritual Well-Being ......................121

7. Interaction of A-I Religious Discrepancy and MSE on ESWB ...............................122 


\section{REVIEW OF THE LITERATURE}

Judaism is a religious anomaly, a combination of spiritual, cultural, and ethnic identities that create an experience that is quite different from the typical American religion. The common understanding of Judaism begins with its role as a religion: a set of shared practices, beliefs, laws, and values that influence relationships with oneself, others, the environment, and the transcendent (Koenig, McCullough, \& Larson, 2001). Similarly, Pargament (1999) defined religiousness as the organizational, ritual, and ideological constructs utilized in the search for the sacred, oftentimes measured through the set of distinct practices established through religious dogma. However, a strictly religious interpretation of Judaism ignores the sizable and growing population of American Jews that do not identify with the religious principles of their ancestors but still self-identify as Jewish (Klaff, 2006). In his exploration of Judaism within the multicultural revolution of psychology, Langman (1999) asserted that a purely religious approach towards defining Jewish identity was a misconception, devaluing the addition of Jewish identity as a religious group, a people, an ethnicity, a culture, and a civilization. Worded from a sociological viewpoint, "Jewishness disrupts the very categories of identity because it is not national, not genealogical, not religious, but all of these in dialectical tension with one another" (Boyarin \& Boyarin, 1993, p. 721). Therefore, a thorough exploration of American Jewish identity must balance both religious and cultural factors. 
For Jewish individuals, Judaism is just one self-concept within an overall identity and is often influenced by expectations created by the self or by external systems. While Rogers (1954) established a rich empirical foundation of the role of personal selfdiscrepancies, few empirical investigations have explored the effect of religious selfdiscrepancies on an individual's overall well-being. If religion is a significant aspect of one's self-concept, then the failure to meet standards of Jewish identity may play an important and therapeutically relevant role in one's psychological and spiritual functioning. Continuing Schlosser's (2006) call for affirmative therapy with Jewish clients, this exploration of Jewish identity and self-discrepancies can help clarify Judaism's role within each individual's experiences.

\section{Judaism as a Religion}

The religion of Judaism is a monotheistic theology based on writings of the Torah (i.e., the first five books of Moses), the Old Testament, the teachings of the Prophets, and the Writings of influential Rabbis; together, the literary foundation of Judaism is found within the $\mathrm{TaNaKh}$, an anagram that represents the totality of the above writings. Cohen (2002) summarized the 13 principles of Jewish faith as enumerated by the great $12^{\text {th }}$ century Rabbi and Jewish philosopher Maimonides. At minimum, Judaism implies the belief 1) in God, 2) that God is one, 3) that God does not exist in a physical state, 4) that God existed before anything else, 5) that a proper life serves God, 6) that there have been true prophets, 7) that Moses was the greatest prophet, 8) that the Torah was given by God to the Hebrew people, 9) that additions or subtractions to the written or oral Torah are not permissible, 10) that God knows the actions of people, 11) that God reward those that follow Judaic law and punishes violations, 12) that the messiah has not come but will 
come at the proper time, and 13) that the dead will be resurrected in the world to come. The Torah lists 613 commandments that are to be followed by observant Jews, including the Ten Commandments that specifically add observation of the Sabbath and significant moral imperatives to the requirements. Overall, Judaic teachings and practices primarily focus on three responsibilities designed for personal, spiritual, and social growth: Teshuvah (repentance), Tefillah (prayer), and Tzedakah (charity).

\section{Cultural Practices of American Jews}

The traditions of Jewish culture often extend the religious experiences, focusing on the values, attitudes, behaviors, and community atmospheres that encompass Jewish lifestyles (Friedlander et al., 2010). Official prayer services require a quorum of 10 participants (called a minyan), enhancing the importance of community and social support in religious and cultural realms. The plethora of Jewish holidays leads to many community activities, including fasting on Yom Kippur and Easter, avoiding chametz (i.e., leavening) during Passover, lighting candles on Hanukkah, and building natural huts for Sukkot. A Jewish life includes many Judaic milestones, including male circumcisions, receiving a Jewish name, becoming Bar or Bat Mitzvah, participating in Confirmation, and traditional marriage (e.g., breaking the glass and standing under a chuppah) and funeral practices. While political and diplomatic beliefs may differ, Jews often demonstrate a strong connection to Israel due to the location as the cultural birthplace of the Jewish people. Individual Jewish experiences greatly vary in the breadth and consistency of upholding the above religious and cultural Jewish experiences, and while assumptions of an individual's Jewish identity should be avoided, qualitative differences in expectations and experiences are seen across Jewish denominations. 
Jewish denominations. Denominations of Judaism are typically distinguished by the level of adherence to traditional religious laws, principles, and rituals, otherwise known as Halakha. As discussed later, while there are common patterns of religious and cultural observance specified by each denomination's expectations, individual differences in Jewish experiences influences how one may view their own Jewish identity, including one's success or failure in meeting expectations (Schlosser, 2006). Overall, stricter adherence to specific religious practices has successfully differentiated between denominations (Friedlander et al., 2010); in order of most to least traditional, the denominations are Hasidism, Orthodox, Conservative, Reform, and secular Judaism. Summaries of the identity foundations of primary Jewish denominations are included below in order of chronological development (Schlosser, 2006);

Orthodox Jews adhere to three distinct elements of Jewish life: following kosher dietary laws, observing all traditions and prohibitions of the Sabbath, and following laws of family purity (e.g., separation of men and women during religious services). Meaning "correct belief", Orthodox Jews follow Halakhic law, which legislates behavior for nearly any possible situation or action (Telushkin, 1991). Most will pray multiple times a day, conduct services entirely in Hebrew, and wear some of the traditional Jewish clothing, such as males wearing Yarmulkes.

Hasidim are considered ultra-Orthodox Jews and are easily identified by their appearance: males traditionally wear black hats and clothing while growing peyos (i.e., side curls), and women wear conservative long dresses. In contrast to Orthodox Jews, the Hasidim immerse themselves in Jewish life and seek minimal interaction with secular 
culture. They also consider the Torah to be the literal translation of God's law and will frequently speak Yiddish, a combination of the Hebrew and German languages.

Beginning in the 1800 s, the Reform movement sought to modernize Judaism, enabling an integration of the religious and secular environments of the period in a way that Orthodox Judaism inhibited. The least strict denomination in following Halakha, Reform Judaism focuses more on community and cultural practices rather than religious beliefs and dogma. Services are typically held predominately in English while the prayers are recited in Hebrew, kosher and purity laws are either minimally followed or disregarded, and there is less focus on Torah commandments and more on overall moral values and social justice (Telushkin, 1991). Sabbath adherence is encouraged, but weekly synagogue attendance is comparatively low.

Conservative Judaism became the middle-ground between Reform and Orthodox denominations, contending that Orthodoxy and Halakhic law need to adapt to new innovations and environments but that Reform Judaism moved too far away from Torah rituals. Women are increasingly included in ritual life, services are conducted mostly in Hebrew, and adherence to kosher laws varies widely within the congregation.

While overall adherence to Halakha can differentiate the various denominations, many common cultural experiences are found across nearly every Jewish congregation and symbolize traditional values, attitudes, and behaviors. Some cultural aspects, such as dating or marrying a Jew, practicing social justice, being active in Jewish communities, and supporting Jewish-owned businesses, can even be maintained by those that would classify themselves as secular Jews. Cultural engagement is less variable across denominations as compared to religious participation and Halakha observance, consistent 
with the goals and expectations of each denominational experience (Friedlander et al., 2010). Although religious and cultural practices differ across denominations, one may experience dissonance if they feel they are not closely aligned with the expectations of their individual Jewish community.

American Jewish demographics. As of 2011, there are an estimated 6.5 million Jews living in the United States, rivaling the Jewish population of Israel and constituting $2.1 \%$ of the total American population (Sheskin \& Dashefsky, 2011). While the American Jewish population has not significantly decreased over the past decade, factors such as low fertility rate, increased intermarriage, relatively high percentage of elderly population ( $22 \%$ above 65 , as compared to a national average of $16 \%$ ), and renouncement of Jewish self-identification are contributing to an overall decrease in population numbers. American Jews tend to be highly educated, with $24 \%$ earning a graduate degree and 55\% a bachelor's degree. Jews are proportionately more likely than non-Jews (59\% and 46\%, respectively) to be employed in management, business, or professional/technical positions. The high levels of education and job status contribute to more than $75 \%$ of the American Jewish population earning annual incomes in excess of $\$ 50,000$ (U.S. Religious Landscape Survey, 2008).

While overall Jewish populations may not be undergoing significant changes, fluctuations across and between the various denominations shape current American Jewish identities. As of 2001, self-reported categorization showed the current American Judaic population to be $10 \%$ Orthodox, 27\% Conservative, 35\% Reform, 2\% Other (e.g., Reconstructionist), and 26\% as "Just Jewish" or secular (Ament, 2005). In comparison, when asked within which denomination each individual was raised, $20 \%$ reported 
Orthodox, $33 \%$ Conservative, $26 \%$ Reform, $1 \%$ Other, and only $20 \%$ as secular, illustrating a trend of increasing secularization and decreasing religious participation.

Religious and cultural variations may also exist depending on the geographical history of Jewish individuals (Langman, 1999; Schlosser, 2006). Most Jewish people belong to one of three lineages. Ashkenazic Jews, representing the most populous lineage of American Jews, trace their history to Eastern Europe, including Germany, Poland, Hungary, and Russia. Sephardic Jews trace their lineage to Spain or Portugal, and Mizrachim Jews find their roots in Northern or Western Africa. While Maimonides' 13 tenets remain consistent, the cultural expressions of Judaism differ across lineages, including ceremonial practices, typical clothing, and traditional foods and hymns. As the above demographic factors may influence Jewish experiences above and beyond simple denominational identification, understanding the development of individualized Jewish identities, including the perceived expectations for the specific self-concept, is required.

\section{Jewish Identity}

Unlike previous generations, contemporary American Jews are individually defining their own Jewishness based on both religious and cultural foundations, a construct Cohen and Eisen (2000) termed the "sovereign self." Idiosyncratic identity development, rather than relying on expectations or normative behaviors, has significantly altered both the conceptualization and measurement of Jewish identity and experiences. The original exploration of Jewish identity sought to measure the "Jewishness" of the American Jewry, as if there was a traditional Jewish yardstick that awarded inches for years of early Jewish education, synagogue attendance, participation 
in extracurricular Jewish activities, and strict observance of Jewish laws and responsibilities (Charme, Horowitz, Hyman, \& Kress, 2008; Horowitz, 1999).

Jewish identity could be measured by comparing an individual's experience or expression of Judaism against a normative, maximal criteria of Jewishness as defined by Simon Herman (1977; in Horowitz, 1999): 1) Judaism is experienced as a national and religious entity; 2) Judaism occupies a position of centrality in one's life space; 3) being Jewish has a positive valence; 4) the Jewish community serves as a reference source for how to live in other significant spheres of one's life; and 5) one performs daily living activities in accordance with distinctively Jewish norms of the group. The focus on daily Halakhic practices and centrality of such an identity within one's self-concept stems from a norm of Orthodoxy.

The normative operationalization of American Jewishness became problematic as successive generations moved towards secularization, coinciding with reduced religious practice and ethnic solidarity within Jewish communities. If the yardstick of Jewish identity remained transfixed in the Orthodoxy of Judaism, then the majority of American Jews would fall short of the yardstick, falling into the category of "less than Ideal" or not being a "good enough Jew" (Horowitz, 1999). While this contention may be accepted by some individuals from more fundamental denominations, such a conceptualization of the American Jewish experience would be disingenuous and rejecting through a psychological and sociological lens (Charme et al., 2008; Horowitz, 2002; Schlosser, 2006).

The exploration of Jewish identity shifted focus from externally supported facts of religiousness towards the internally central, personal, and subjective experiences of one's 
worldview (Horowitz, 1999). The yardstick of religious principles and guidelines does not truly measure the effect of how one's idiosyncratic Jewishness is defined and how it influences internal, interpersonal, and transcendent-oriented relationships. There are those that consider themselves Jewish by name only, some that regularly participate in family and community traditions but only go to synagogue for High Holy Day services, and those that consider Judaism salient within every moment of their lives.

While religious expressions remained integral to these experiences, cultural participation began carrying more credence (Horowitz, 1999). The theoretical response to Herman's Jewish yardstick lay within Kelman's (1999) social influence theory, conceptualizing group identity as being influenced by behavioral compliance, cognitive identification, and affective internalization of the identity development process. Social influence theory contends that group identity is just one type of external input that must still become individually incorporated into the personal identity to become relatively impactful. Similar to the "sovereign self" (Cohen \& Eisen, 2002), Jewish identity is seen as constantly being developed through individualized strategies focused on making meaning from their group identity, not prioritizing obligation (Horowitz, 1999). As Kelman (1999) stated in applying this social influence view to the conceptualization and development of Jewish identity:

There is good reason to argue...that in the complex, pluralistic, rapidly changing world in which we now live, the model presented here is more conducive to the incorporation of Jewish identity into an authentic, integrated personal identity. The alternative may be a Jewish identity that is offered in maximal form but accepted in minimal form (p. 20). 
As opposed to the yardstick proposal, idiosyncratic development of Jewish identity allows for myriad combinations of beliefs, practices, values, and community involvement without requiring the category of "less than Ideal" Jewish self-identities. Jewish identity can be conceptualized as an intertwined double-helix, illustrating how Jewish identity interacts with other sub-identities and melds with one's individual DNA, including "hereditary" influences through tradition and expectation, personal choices, and the environment (Charme, Horowitz, Hyman, \& Kress, 2008). The strength, content, and consistency of Jewish identity can fluctuate, change, ebb, and flow in response to personal and environmental contexts and life events, but the genetic code of Jewish identity remains.

Even with the primary conceptualization of American Jewish identity as idiosyncratic desires, expectations, and experiences, the influence of the normative yardstick can not be forgotten. While more traditional denominations place great significance on properly measuring up, Jews from all religious and cultural engagements may be cognizant of the Judaic expectations, obligations, and duties held by the religious community (e.g., synagogue, Rabbi, and family traditions).

Regardless of denomination, do American Jews measure themselves against the original normative yardstick? If so, are there religious, spiritual, or mental health consequences stemming from discrepancies between one's current Jewish identity and the measure of Judaism they wish they were or they feel they should be? These questions form the crux of the current research agenda. 


\section{Foundations of Religious Identity: Comparing Judaism and Christianity}

In recent decades, research pertaining specifically to Judaism has increased for two primary reasons: the increasing realization that empirical results from Christian samples should not be generalized to other religious traditions without replication, and the increased need to understand the religious and cultural experiences of minority identities consistent with multicultural perspectives (Rosmarin, Pargament, Krumrei, \& Flannelly, 2009a). While the Old Testament offers a shared theological foundation, the introduction of Jesus as divinity catalyzed the separation of the religious followings, leading to significant differences in the religious and cultural identities of Christian and Jewish individuals.

Judaism and Christianity differ theoretically through the method of defining one's membership in a religion or culture (Morris, 1997). Christianity is defined as an "assent" religion, requiring the individual to agree with and uphold a set of shared truths, values, and beliefs. Especially emphasized by Protestantism, adherence to specific dogmatic beliefs is essential for Christian membership in order to achieve closeness to God and eternal salvation.

Alternatively, Judaism is categorized as a "descent" religion because membership is gained through biological descent and the continuation of the ethnic heritage. Judaism typically places a premium on social connectedness, traditional practices, and participating in community improvement, while placing faith and spirituality as lower (but still important) priorities (Cohen, 2002; Rosmarin, Pirutinsky, Pargament, \& Krumrei, 2009c). Prager and Telushkin (1981) stated that the difference between these Abrahamic religions is not in the divinity of Jesus but rather the relative importance of 
internal states versus behaviors; Judaism is the religion of the deed rather than the religion of the creed.

In a series of studies, Cohen and colleagues supported the assent-descent discrepancy between Judaism and various Christian denominations. First, Cohen (2002) found that religious belief, spirituality, and coping with stress by turning to God were more prevalent and more predictive of life satisfaction and happiness in Catholics and Protestants as compared to Jews. Jewish participants reported a lower belief in divine locus of control and a higher importance in congregational support for predicting life satisfaction, all consistent with the presentation of a descent religion.

The difference between religions of the creed and deed was tested by presenting Protestant and Jewish participants various scenarios involving inappropriate mental states absent of behavioral acts, such as secretly disliking one's parents but acting respectfully, having sexually promiscuous and adulterous thoughts, or thinking about poisoning an enemy’s dog (Cohen \& Rozin, 2001). While both Jews and Christians agreed that acting out these actions were immoral, Jews were less likely to morally condemn mental states of the hypothetical subjects. Protestants may believe that inappropriate mental states are controllable and are more likely to lead to morally wrong actions, while Jews do not consider internal mental beliefs to significantly contribute to the perceptions of one's identity.

Theologically, the lack of credence to negative mental states in Judaism is found in the Talmud, stating that "A good thought is regarded as a good deed...but that the Holy One, blessed be He, does not regard a bad thought... as an actual deed" (Kiddushin, p. 40a; Cohen, Malka, Rozin, \& Cherfas, 2006). Judaism teaches that all people have the 
inclination to do evil (yetzer rah) or good (yetzer tov), and that it is one's obligation to rise above negative temptations; as long as these negative thoughts do not interfere with performing good deeds, inherent inclinations are not considered immoral (Cohen \& Rozin, 2001). However, the previous pattern of severity in moral judgment alternates when considering physical actions, as Jews are more likely than Protestants to argue that specific severe offenses are considered unforgivable (Cohen et al., 2006); again, the intentional focus of Judaism maintains physical participation as superior to internal beliefs, a distinction that may allow Jews to properly identify self-discrepancies through lack of actions and deeds.

The relative importance of religious belief and religious practice also illustrates core differences between descent-focused Judaism and assent-oriented Christianity. Cohen, Siegel, and Rozin (2003) found that both Jews and Protestants rated religious practice as highly essential in defining religiousness. However, while Protestants placed religious beliefs as equally important to religiousness, Jews considered maintaining specific beliefs about God, the afterlife, the soul, or scientific explanations as significantly less important. To confirm these differences, the researchers found that religious practice predicted self-rated religiosity for both Jews and Protestants, but religious beliefs added additional variance only for Protestants. In general, Jews perceive their religious self-identity primarily through participation in Judaic practices, while Christians equally address practices and beliefs to identify their religiosity.

\section{Ethnic Jewish Identity}

As a descent-oriented religious culture, and in light of the relatively smaller role that religious faith maintains within Jewish identity, empirical research has further 
explored the importance of ethnic identity to Judaism. As an aspect of one's overall social identity, ethnic identity is defined as the part of an overall self-concept stemming from one's membership to a social group, including the knowledge, value, and emotional significance attached to one's belonging to that group (Tajfel, 1981). Phinney and Ong (2007) developed a multidimensional conceptualization of ethnic identity that includes eight specific aspects: self-categorization, commitment and attachment, values and beliefs, ethnic behaviors, identity importance and salience, identity exploration, in-group attitudes and evaluation, and relationship to other identity constructs.

Ethnic identity begins with self-identification through inclusion into a category or addition of a label. Within Judaism, while some secular Jews may self-identify as "just Jewish," others more closely self-identify through their specific denomination; through an idiographic lens, the label is less important than the meaning and expectations connected to such a category.

Arguably the most important element of ethnic identity consists of one's commitment, sense of belonging, and attachment to the group (Ponterotto, Gretchen, Utsey, Stracuzzi, \& Saya Jr., 2003). Although adherence to specific ethnic values and beliefs is a common indicator for closeness to one's group, commitment is viewed through an emotional lens and illustrates the strength of one's connection to the ethnic facet of one's identity. The extent that one feels accepted by and committed to their ethnic identity may alter how self-discrepancies within that facet affect overall wellbeing.

Central to Jewish identity, ethnic behaviors are just one aspect of overall ethnic identity. Ethnic behaviors, such as speaking native languages, eating traditional foods, 
and participating in cultural events, may explicitly express one's identity but should be considered the external demonstration of one's internal ethnic identity, not the encapsulation of one's identity. The intensity and frequency of the presence of ethnic beliefs, values, behaviors, and sense of belonging contribute to the perceived importance or salience of the specific ethnic identity; high saliency appears to be more integral to overall well-being for those with high ethnic identity as compared to low ethnic identity (Yip \& Fuligni, 2002).

Similar to identity developmental models (Marcia, 1980), exploration is a key facet to ethnic identity. While central to the adolescent experience, exploration of one's ethnic identity is often a lifelong endeavor, influencing the fluidity of one's identity. Part of the exploration process is developing attitudes, either positive or negative, concerning one's specific group membership. Pride and positive feelings towards one's group are linked with an achieved ethnic identity status (Phinney, Cantu, \& Kurtz, 1997; Roberts et al., 1999) and daily happiness (Kiang, Yip, Gonzales, Witkow, \& Fuligni). Positive attitudes about one's membership in the group and of overall group attributes is the primary mechanism for ethnic identity to act as a buffer against discrimination and negative in-group attitudes (Tajfel, 1978). The last category of ethnic identity described by Phinney and Ong (2007) is its relationship to other spheres of identity, e.g., national identity. The majority of research points to ethnic and national identities as being either positively correlated or uncorrelated, allowing for high identification within multiple identities simultaneously (Berry, 2003).

Ethnic identity across Jewish denominations. Two qualitative studies, one focusing on Conservative Jews (Altman, Inman, Fine, Ritter, \& Howard, 2010) and 
another interviewing Jews from multiple denominations (Friedman, Friedlander, \& Bluestein, 2005), found themes consistent with the ethnic identity categories enumerated above. Members from all denominations experienced the pressure of minority status, endorsing both American and Jewish identities but often feeling anxious or forced to determine which environments are safe to express the latter. Conservative Jews experience and/or report more discriminatory behaviors due to their higher involvement in both American and Jewish realms, thus offering more opportunities to encounter biases and prejudice (Altman et al., 2010; Friedlander et al., 2010). While marginalization and discrimination were primary foci in both denominations, a sense of pride and community appeared to act as a buffer against negative in-group attitudes and lower collective selfesteem. Neither qualitative study found endorsement of anti-Semitism or traits of the "self-hating Jew" that can develop from internalized prejudice (Schlosser, 2006), although the studies did not include samples of lower Jewish self-identification.

There appeared to be a positive relationship between cultural identification and religious observance, with primary attention on traditions and practices that contribute to the sense of community and the generativity of identity onto one's children; as one participant from Altman et al. (2010) stated: "You don't need to be very religious to be considered Jewish; there's also that importance of community, appreciation of your ethnicity, and being with Jewish people" (p. 166). Living a Jewish lifestyle and upholding Jewish values, such as practicing Tikkum Olam, i.e., "repairing the world," is central to Jewish identification.

The role of specific practices highlighted an area of contention and concern amongst the interview participants, as some felt judgment and alienation from more 
traditional denominations or their own Jewish community for not being "Jewish enough." Importantly, Jews from all denominations, including Orthodox, expressed a desire to increase their religious and cultural practices. Guilt was the common affective consequence of this perceived discrepancy between the individual's current religious participation, what they desired to be for a specific reason (e.g., generational transmission of Judaism), and what they believed other Jews expected of them.

While quantitative studies with Jewish participants are sparse, Jewish ethnic identity tends to be highly correlated with positive in-group attitudes, perceived salience of Jewish identity (Goodman, 2002), religious participation (Weisskirch, 2004), and global spirituality (Kakhnovets \& Wolf, 2011). However, the limited empirical evidence has found only weak or insignificant correlations between Jewish ethnic identity and psychological well-being constructs, such as anxiety and depression (Goodman, 2002; Kakhnovets \& Wolf, 2011).

\section{Judaism and Mental Health}

Religious beliefs and practices have consistently been linked with lower levels of anxiety and depression while being positively related to life satisfaction and well-being (see Koenig, Ford, George, Blazer, \& Meador, 1993 for review). However, the vast majority of research within this field has either focused predominately on Christian samples or explored the relationships through a Christian conceptualization of religiosity. Cohen (2002) already demonstrated that religious beliefs have little impact on life satisfaction of Jews, but does the same pattern generalize to mental health outcomes? 
Judaic denominations appear to interact with the salience of religious beliefs in its effect on mental health. After controlling for religious practices, lower religious beliefs contributed to additional anxiety and depression for Orthodox Jews and Protestant Christians but not for non-Orthodox Jews (Rosmarin et al., 2009c). Amongst responses from Orthodox Jews, religious practices and beliefs accounted for $19 \%$ of variance in depression and $12 \%$ of anxiety, illustrating the power of religiosity and connectedness to God as a protective power for the more traditional Jews (Abromowitz, Huppert, Cohen, Tolin, \& Cahill, 2002).

A more nuanced differentiation between Orthodox and less traditional denominations was found while exploring the effect of spiritual struggles on physical and mental health (Rosmarin, Pargament, \& Flannelly, 2009b). A spiritual struggle is defined as tension and strain on spiritual issues within oneself, with others, and with the divine, and is often identified through a higher frequency of negative religious coping strategies (Pargament, Murray-Swank, Magyar, \& Ano, 2005; Rosmarin et al., 2009c). Across religions, spiritual struggles have been consistently linked to anxiety and negative affect (Ano \& Vasconcelles, 2005), depression and suicidality (Exline, Yali, \& Sanderson, 2000), and lower overall well-being (McConnell, Pargament, Ellison, \& Flannelly, 2006).

The contention that spiritual struggles are more negative and impactful for more religious individuals (Pargament, Tarakeshwar, Ellison, \& Wulff, 2001) was found within a Jewish sample by Rosmarin et al. (2009b). While the presence of spiritual struggles were related to lower physical and mental health for Jews of all denominations, the correlations were modest at best ( $\mathrm{r}=-.14$ and -.19 , respectively). However, within this same study, the pattern for Orthodox Jews $(\mathrm{N}=168)$ deviated from the non-Orthodox 
sample, showing significantly larger deficits in physical and mental health for moderate spiritual struggles but also experiencing an increase in well-being during high-intensity spiritual struggles. These results are representative not only of the acceptance of religious argument and debate within traditional Jewish study, but also points to the higher priority of religious practice over beliefs. Spiritual struggles and negative religious beliefs, nearly always problematic in other religions, may not be as salient to Jewish populations. As a religion of the deed rather than religion of the creed, the acceptance of spiritual struggles is observed even during one of the darkest times in Jewish history, as evidenced by the following occurrence in Auschwitz:

Three great Jewish scholars — masters of Talmud, Halakha (Jewish law), and Jewish jurisprudence - put God on trial, creating in that eerie place a rabbinic court of law to indict the Almighty. The trial lasted several nights. Witnesses were heard, evidence was gathered, conclusions were drawn, all of which issued finally in a unanimous verdict: The Lord God Almighty, Creator of Heaven and Earth, was found guilty of crimes against creation and humankind. And then...the Talmudic scholars looked at the sky and said "It's time for the evening prayers," and the members of the tribunal recited the evening service. (Brown, 1995, p. vii)

\section{Self-Discrepancy Theory}

Beginning with William James' exploration of self-concept within personality, the field of psychology has explored the consequences stemming from a failure to meet one's own expectations (James, 1890; Watson, Bryan, \& Thrash, 2010). According to Rogers (1959): 
Self-concept is the organized consistent conceptual gestalt composed of perceptions of the characteristics of 'I' or 'me' and the perceptions of the relationships of the 'I' or 'me' to others and to various aspects of life, together with the values attached to these perceptions. It is a gestalt which is available to awareness though not necessarily in awareness. It is a fluid and changing gestalt, a process, but at any given moment it is a specific entity. (p. 200)

The influences of other people and of one's environment, either real or perceived, often establish expectations that the self must match in order to obtain the positive regard of others and consider oneself worthy of praise. Such conditions of worth may become internalized, establishing characteristics and values that one may or may not have but that are desired or required to maintain positive regard from the self and from others. These conditions may come from any number of smaller identities, roles, and relationships within one's personality gestalt. Central to his person-centered theory, Rogers (1951) theorized that a discrepancy between the way one actually sees oneself (Actual self) and the 'I' or 'me' that one would truly like to see (Ideal self) is the primary determinate of negative psychological states.

Expanding self-discrepancy theory, Higgins (1987) theorized the existence of three basic domains of the self, representing the attributes the person perceives from varying viewpoints. While the Actual and Ideal selves maintain Rogers' conceptualization, Higgins identified the "Ought self" as the attributes one perceives they should or ought to possess, specifically related to a sense of duty, obligation, or responsibility (Higgins, Bond, Klein, \& Strauman, 1986). Self-state representations are also defined by the standpoint of the self, such that Actual, Ideal, and Ought selves can be 
seen from the one's own perspective or the standpoint of significant others; just as conditions of worth stem from the self, others, and environments, each perspective offers a "guide for being" based off of a set of standards (Higgins, Strauman, \& Klein, 1986).

A central tenant of Higgins' (1987) theory is that people are motivated to find congruency between one's self-concept and one's self-guides. As with Rogers' theory, larger perceived discrepancies lead to more emotional and cognitive discomfort. However, Higgins adds to the self-discrepancy literature by conjecturing that specific self-guides will uniquely predict different negative psychological states.

The perception that the Actual self is failing to maintain the attributes and standards of the Ideal self often leads to dejection-related emotions, such as sadness, disappointment, and depression (Higgins et al., 1986a; McDaniel \& Grice, 2008). The Actual-Ideal (A-I) discrepancy highlights the failure to obtain positive outcomes in the search for the ideal self, including the unfulfilled goals and desires of the individual. On the other hand, the perceived presence of negative outcomes is theorized to coincide with the belief that one's actual self is not fulfilling the sense of duty, obligation, or responsibility held by the standards of the Ought self. The Actual-Ought (A-O) discrepancy is expected to predict anxiety-related symptoms (including guilt, shame, fear, and nervousness) due to the sense of punishment that coincides with failure to live up to the expectations and standards of others (Higgins et al., 1986b; Large \& Marcussen, 2000). The strength of the emotional consequence is affected not only by the magnitude of the discrepancy but also by the accessibility or awareness of the discrepancy. Identity facets that are highly salient to one's self-concept, such as Jewish identity, will be more sensitive to emotional reactions due to incongruences (Large \& Marcussen, 2000). 


\section{Empirical Support for Self-Discrepancy Theory}

Rogers and colleagues were the first to research the relationship between ActualIdeal discrepancies and emotional distress, finding that reduced discrepancies coincided with decreased anxiety and depression within the context of client-centered (BarrettLennard, 1962; Rogers \& Dymond, 1954; Meyer, 1981) and cognitive-behavioral or interpersonal therapies (Strauman et al., 2001). Moretti and Higgins (1990) found the identification and exploration of A-I discrepancies helped explain the presence of low self-esteem better than simply measuring Actual self-ratings only; a parallel association can be made to the idea that Jewish identification solely through denominational labels may not fully explain the effect of Jewish identity on overall self-concept. Clinically significant differences have also been supported: those diagnosed with depression have larger A-I discrepancies than non-depressed participants, while those with anxiety-related diagnoses have larger A-O discrepancies than non-anxious participants (Strauman et al., 2001).

Observing that people responded to negative events in significantly different ways based on the perspective and magnitude of self-discrepancies, Higgins (1987) theorized and initially supported a model of unique prediction: larger Actual-Ideal discrepancies uniquely predicted dejection while larger Actual-Ought discrepancies uniquely predicted agitation. In his second study, Higgins manipulated the saliency of specific discrepancies and found that the primed self-guide led to increases in the appropriate emotional reaction (Higgins, 1987; Large \& Marcussen, 2000). Studies with undergraduate student samples have shown similar discrepancy-consequence patterns (Hardin \& Leong, 2005; Higgins, Klein, \& Strauman, 1985), and a 2-month longitudinal study supported the 
ability of A-I and A-O discrepancies to predict depressive and anxious symptoms, respectively (Higgins et al., 1986b).

While self-discrepancies have consistently been linked to negative affect and pathology, the unique predictive ability of discrepancies on specific outcomes has been empirically challenged (Hardin \& Lakin, 2009; McDaniel \& Grice, 2008). Some studies have shown both discrepancies to be predictive of only anxiety (Hart, Field, Garfinkle, \& Singer, 1997), only depression (Tangney, Niedenthal, Covert, \& Barlow, 1998), or mixed effects (Ozgul, Heubeck, Ward, \& Wilkinson, 2003; Scott \& O’Hara, 1993); one instance of mixed effects was the finding that A-O discrepancies uniquely predicted anxious affect but both discrepancies predicted depressed mood (Phillips \& Silvia, 2010). Other studies have shown that one of the self-discrepancies does not account for additional variance for either of the emotional disturbances (Bruch, Rivet, \& Laurenti, 2000; Bryan, Watson, Babel, \& Thrash, 2008).

The conflicting results concerning self-discrepancy theory and its measurement may be due to the close proximity and developmental relationships between A-I and A-O discrepancies. More specifically, it may be difficult for participants to properly draw distinctions between the Ideal and Ought selves (Ozgul et al., 2003; Tangney et al., 1998). In fact, Tangney et al. (1998) reported that the most frequently asked question during the data collection was "What's the difference between Ideal and Ought?" This overlap has been demonstrated in significantly high correlations between the A-I and AO discrepancies across all perspectives. While Higgins (1987) reported intercorrelation ranges from .53-.76, more recent studies have reported intercorrelations ranging from $.67-.80$ (Tangney et al., 2008) to even .92 (Hart et al., 1997). Some have argued that these 
high intercorrelations suggest that only a single discrepancy is being measured (Gramzow, Sedikides, Panter, \& Insko, 2000; Tangney et al., 1998), while others continue to find evidence for two distinct discrepancies (Phillips \& Silvia, 2010; Watson et al., 2010). Another plausible explanation for inconsistent results may be related to the limited ability of the utilized instruments to discriminate between anxiety and depression; proper consideration of outcome measures is further addressed in the Methods section.

\section{Current Self-Discrepancy Instruments}

As individuals internalize the standards and expectations held by society, ethnic or religious groups, and significant others, the infusion of obligations and duties into the perception of one's own goals and desires makes the differentiation of Ideal and Ought selves problematic (Watson et al., 2010). However, the limited ability to separate these constructs may be due to problematic methods and instruments that are designed to identify self-discrepancies. Due to inconsistent support for the hypothesis of unique prediction, extremely high construct inter-correlations, and the possibility of a low prevalence of any discrepancies (Boldero \& Francis, 2010), researchers began analyzing the psychometric properties of various methods to measure differences between the Actual, ideal, and Ought selves.

The majority of empirical studies that have explored self-discrepancies utilized Higgins's Selves Questionnaire (Higgins et al., 1986a), an idiographic measure that asks participants to generate a list of attributes for each domain of the self and possibly from various standpoints (Hardin \& Lakin, 2009). Discrepancies are determined by comparing the list of adjectives formulated by the participant for each category, coding responses for matches and mismatches; the larger the difference between matches and mismatches 
between domains of the self, the larger that specific discrepancy. The intention of this method is to have participants extemporaneously identify attributes belonging to each self-domain, hopefully highlighting the importance of these attributes to the individual (Higgins et al., 1986a). However, this method has been criticized for consistent test-retest reliabilities lower than .70 , poor discriminant validity due to poor differentiation between ideal and ought selves, length and difficulty for the participant to complete, and complex and frequently subjective scoring processes (Hardin \& Lakin, 2009; Watson, Bryan, \& Thrash, 2010).

Other idiographic measures have been created (Carver, Lawrence, \& Scheier, 1999; Watson, 2004), typically instructing participants to rate the presence of individually-identified adjectives on each of the three self-perspectives (i.e., Actual, Ideal, and Ought) and then calculating differences to identify self-discrepancies. Watson's (2004) Self-Concept Questionnaire-Personal Constructs instruments has shown improved test-retest reliability $(r=.81)$, appropriate test-criterion relationship to neuroticism (Watson \& Watts, 2001), and strong internal consistencies for A-I $(\alpha=.92)$ and $\mathrm{A}-\mathrm{O}(\alpha=.91)$ discrepancies.

Due to possible advantages in utility, researchers have compared idiographic instruments to nomothetic measures, such as adjective lists given to participants to rank within each self-domain, to determine the appropriate method for self-discrepancy research; so far, the results appear to be inconsistent. Watson et al. (2010) compared idiographic, nomothetic, and abstract (i.e., choose the overlap of circles that best represents the relationship between your actual and ideal selves) measures and found their idiographic measure to have the best 
psychometric properties, specifically in its internal consistency, test-retest reliability, and discriminate validity by differentiating between the two discrepancies. It was noted that the nomothetic adjective list still met minimal psychometric properties, while the abstract measure was weak but could still be useful due to its fast administration.

Not all researchers have agreed that the idiographic instruments are the best fit for this field of research. In one of the first major studies to challenge Higgins's theory, Tangney et al., (1998) found that the idiographic and nomothetic measurements demonstrated nearly identical psychometrics and construct relationships, including very high discrepancy inter-correlations. McDaniel and Grice (2008) also compared the two types of measures and found that only the nomothetic measurements of self-discrepancies contributed to psychological outcomes. One other solution was conceived by Hardin and Lakin (2009), who created the Integrated Self-Discrepancy Index as a combination idiographic-nomothetic instrument; during administration, participants first create their own list of attributes but are then given a list of 100 adjectives to allow for desired modifications, and then each is ranked according to the self-domain. Results showed that the instrument better differentiated between discrepancies and fully supported Higgins' original theory. Overall, it appears that there is insufficient justification to avoid using nomothetic instruments for identifying the presence and magnitude of self-discrepancies.

\section{Jewish Identity and Self-discrepancies}

The author's review of self-discrepancy literature discovered a nearly complete exclusion of religious identity or behavioral constructs, let alone studies that have involved Jewish participants. Lilliston and Klein (1991) related specific selfdiscrepancies to religious coping, finding that A-O discrepancies increased behavioral 
and affective religious coping as compared to those without a discrepancy. This result supported their hypothesis that behavioral coping may be the more appropriate coping response to feeling that one is not living up to the expectations of others or one's community; their hypothesis that A-I discrepancies would increase cognitive religious coping mechanisms, thus attempting to adjust unrealistic definitions of the Ideal self, was not supported.

The only other study found to include self-discrepancy and religious constructs was an unpublished Master's thesis, within which A-I religious discrepancies were related to negative affect for Christians who were typically very attentive to their internal cues (Parker, 2004); it is encouraging to note that significant religious discrepancies from the Ideal and Ought perspectives were identified. Connections to religious or ethnic identity can be made through the few studies that have shown the effects of group identification discrepancies on agitation and dejection-related emotions (Bizman \& Yinon, 2004; Petrocelli \& Smith, 2005).

A primary purpose of this study is to determine if American Jews identify discrepancies between their Actual, Ideal, and Ought Jewish identities. Ideal and Ought Jewish perspectives are prevalent throughout the Jewish community (Altman et al., 2010) and may be impactful at the individual level, although the identification and importance of these perspectives may be influenced by the centrality of one's Jewish identity to overall self-concept. As a part of one's identity, discrepancies between the Actual and either the Ideal or Ought domains of Jewish identity would theoretically contribute to negative affect. Within this study, religious self-discrepancies are expected to affect depression, anxiety, and spiritual well-being. 
The American Jewish Identity Scale (AJIS; Friedlander et al., 2010) will be utilized as a nomothetic, adjective-like scale to measure Jewish identity and calculate religious self-discrepancies from both Actual-Idea and Actual-Ought perspectives. After completing the AJIS from the perspective of their Actual Jewish identity, each participant will complete the instrument only one additional time from either their Ideal or Ought perspective, thus reducing the confusion that may result from identifying both ActualIdeal and Actual-Ought Jewish self-discrepancies within one time period.

\section{Ethnic identity and Jewish self-discrepancies}

An individual's overall ethnic identity may moderate the relationship between self-discrepancies and psychological outcomes, such as anxiety and depression (Phinney, 1992). As previously discussed, Judaism's categorization as a descent religion and the accompanying focus on community closeness has increased the frequency of Judaism being referred to as an ethnicity.

While focusing on racial-ethnic minorities, a meta-analysis by Smith and Silva (2011) found moderate effect sizes for ethnic identity's positive correlations with selfesteem and well-being; while still significant, the effect size for the negative correlation of ethnic identity to depression and anxiety were smaller than the adaptive constructs. Ethnic identity has also been connected to acculturation (Cuellar, Nyberg, Maldanado, \& Roberts, 1997), ethnic self-concept (Phinney, Chavira, \& Tate, 1996), and a positive multicultural worldview (Ponterotto, Baluch, Greig, \& Rivera, 1998).

Within Judaism, higher endorsement of ethnic exploration and commitment appears to be a double-edged sword. On one hand, a strong sense of ethnic identity leads 
to increased collective self-esteem and can offer effective coping resources to deal with stress, mediated by increased seeking of both religious and social-cultural support structures (Dubow, Pargament, Boxer, \& Tarakeshwar, 2000). On the other hand, higher ethnic identity also translates to more perceived discrimination and acculturative stress due to the higher salience of the minority status (Dubow et al., 2000; Friedlander et al., 2010). According to the stress mobilization theory (Bjorck \& Cohen, 1993), the presentation of specific stressors will elicit appropriate coping strategies, just as Jewish individuals perceiving ethnic-related stressors may gravitate towards religious and/or cultural supports.

In addition to general ethnic identification as measured through one's exploration and commitment, Luhtanen and Crocker's (1992) conceptualization views the ethnic selfconcept as both personal and dependent on the individual's evaluation of their social group membership. The four subscales of their Collective Self-Esteem Scale (CSES) include one's own evaluation of the social group (private CSE), their belief of how others evaluate the group (public CSE), the extent one believes they are a good member of the group (membership self-esteem; MSE), and the perceived importance of one's group membership to the overall self-concept (Importance to Identity).

The inclusion of two points of view_-private and public — appears to be closely related to self-discrepancy's references to self- and other-oriented behavioral guides. Bizman and Yinon (2004) found a significant negative correlation between the private CSE and MSE subscales and both Actual-Ideal and Actual-Ought discrepancies; as one's belief of being a good member in a positively-viewed group increases, their Actual self is not perceived as significantly different from their desired identity. The researchers also 
found public CSE to be negatively correlated with Actual-Ideal discrepancies, although the relational strength was smaller than private CSE, suggesting that the impact of outgroup perceptions on individual or in-group self-esteem is minimal.

While highly identified Jewish participants reported stronger private collective self-esteem, lower scorers on Jewish identity still had moderately positive evaluations of their Jewish community (Friedlander et al., 2010). However, membership self-esteem appears to be rarely researched with Jewish samples but may be valuable to help explain the relationship (or lack thereof) between religious self-discrepancies and negative psychological adjustment. Ethnic identity can only be a meaningful psychological variable if it is salient and central to one's overall identity (Phinney, 1996). The feeling that one is a good member of their ethnic identity (Membership self-esteem) and the centrality of their Jewish identity (Importance to Identity) may alter the way Jewish selfdiscrepancies affect psychological and spiritual outcomes. Jewish individuals knowledgeable about the practices and expectations held by Ideal or Ought Jewish identities may perceive discrepancies with their Actual identity but still maintain the belief that they are good members of their Jewish community (high MSE), preventing the presentation of negative psychological outcomes. Another hypothetical participant may deny the presentation of religious self-discrepancies due to low Ideal or Ought expectations of Judaic participation, but feeling like one is not a valuable member of their Jewish collective (low MSE) may still contribute to lowered self-esteem, depression, or anxiety. Similar patterns might also be seen for the Importance to Identity subscale, such that lower salience of Jewish identity to one's overall self-concept may greatly reduce the impact of self-discrepancies on well-being, and vice versa. 


\section{Perfectionism}

The exploration of self-discrepancies requires the comparison of one's Actual self to the expectations and behavioral guides established by others or by one's self-concept. However, what determines which expectations are perceived or are represented by the Ideal and Ought selves? How can two separate Jewish individuals hypothetically report equivalent actual Jewish identities yet only one believe they are not living up to expectations? The perception of self-discrepancies may be a subset of one's overall characteristic of perfectionism (Hankin, Roberts, \& Gotlib, 1997; Hewitt \& Flett, 1991).

A multidimensional construct, perfectionism has been defined as the dispositional striving for flawlessness, the establishment of excessively high standards for performance, the tendency to be overly critical of one's own behaviors, (Flett \& Hewitt, 2002; Frost, Marten, Lahart, \& Rosenblate, 1990; Stoeber \& Childs, 2010), and the defining of self-worth in terms of achieving those standards (Burns, 1980). Perfectionism is often associated with the fear of failure, avoidance of performance tasks that challenge perfectionistic strivings, and self-handicapping behaviors that defend the self from dissatisfaction due to unmet standards (Shafran \& Mansell, 2001).

\section{Perfectionism and Mental Health}

Historically, the exploration of psychological correlates with perfectionism has focused on a litany of negative outcomes. Socially prescribed perfectionism is positively associated with depression (Enns \& Cox, 1999; Flett, Hewitt, Blankstein, \& O’Brien, 1991; Hewitt \& Flett, 1991a; Hewitt, Flett, \& Ediger, 1996; Wyatt \& Gilbert, 1998), negative affect (Molnar, Reker, Culp, Sadava, \& DeCourville, 2006), and maladaptive 
coping (Dunkley, Zuroff, \& Blankstein, 2006; O'Conner \& O'Conner, 2003), while being negatively associated with subjective well-being and satisfaction with life (Bartsch, 2007; Molnar et al., 2006; Saboonchi \& Lundh, 2003). The focus on external control of standards, as present in SPP, appears to contribute to depressive symptoms due to a perceived lack of internal control, an increased sense of hopelessness, and lowered selfefficacy to affect change (Donaldson, Spirito, \& Farnett, 2000; Hart, Gilner, Handal, \& Gfeller, 1998; Shafran \& Mansell, 2001). The connection between SPP and depression appears to be mediated by overall self-esteem, specifically due to the frequent perception of negative criticism that directly hurts one's self-concept (Preusser, Rice, \& Ashby, 1994).

Interestingly, the connection between self-oriented perfectionism and depression and other negative outcomes has demonstrated mixed results (Enns \& Cox, 2002). SOP has been found to be positively (e.g., Dunkley et al., 2006; Kobori \& Tanno, 2005) and negatively (e.g., Frost et al., 1993; Molnar et al., 2006) correlated with negative affect; similar ambivalence has been found for subjective well-being (Bartsch, 2007; Trumpeter, Watson, \& O’Leary, 2006) and adaptive coping (Dunkley et al., 2006; Flett, Russo, \& Hewitt, 1994). Campbell and Di Paula (2002) understand this ambivalence by identifying two different factors within SOP: adaptive Perfectionistic Striving and maladaptive Importance of Being Perfect. Striving towards high expectations can increase motivation and achieved success, leading to higher self-efficacy, self-esteem, and satisfaction with life. However, too much emphasis on meeting these standards in defining one's own selfconcept can be debilitating and increase self-criticism to depressive levels. 
Empirical relationships between perfectionism and anxiety show a pattern parallel to that demonstrated with depression. SPP has been consistently related to the development and maintenance of various anxiety disorders, especially social phobias and obsessive-compulsive traits (Antony, Purdon, Huta, \& Swinson, 1998b). Maladaptive core beliefs may involve the expectation of negative results, the need to obtain perfect social performance to avoid humiliation, the requirement to review and doubt one's work over the fear of mistakes, and the fear of irrational consequences for perceived failures (Heimberg, Juster, Hope, \& Mattia, 1995; Saboonchi \& Lundh, 1997). While strong correlations are typically found between anxiety and SPP, the relationship with SOP is typically in the low to moderate range (Hewitt \& Flett, 1991), and the FMPS-relatable subscale of Personal Standards did not significant differ between community and clinically-anxious samples (Lundh \& Ost, 1996). Stoeber, Kempe, and Keogh (2008) did find that both SPP and SOP were positively correlated with shame and guilt following the failure of a task, suggesting personal and interpersonal aspects of perfectionism.

\section{Perfectionism Measures}

Two primary assessments are currently utilized to measure perfectionism as a multidimensional construct. Hewitt and Flett's (1991) Multidimensional Perfectionism Scale (HMPS) identifies three subsets of perfectionistic to represent personal and interpersonal aspects. Self-oriented perfectionism (SOP) is establishing excessively high standards for oneself and strong motivation to avoid failure, often leading to selfcriticism and self-punishment. Socially prescribed perfectionism (SPP) is characterized by the perception of that others maintain unrealistically high expectations for the individual's behavior and will stringently evaluate their worth based on these standards; 
these beliefs lead to excessive fear of losing approval and the acceptance of others if the conditions are not met (Enns \& Cox, 2002; Stoeber \& Childs, 2010). The last category, Other-oriented perfectionism, is defined as having unrealistically high standards for the behavior of significant others, not pertaining to one's own behaviors.

Frost's Multidimensional Perfectionism Scale (FMPS; Frost, Marten, Lahart, \& Rosenblate, 1990) has a comparable conceptualization of the target construct that includes six subscales: Concern over Mistakes, Doubts about Actions, Personal Standards, Parental Expectations, Parental Criticism, and Organization. Stober (1998) found that a four-factor structure best represented these subscales, renaming them Concern over Mistakes and Doubts, Parental Expectations and Criticism, Personal Standards, and Organization; the last category is often excluded from the overall conceptualization due to the lack of theoretical closeness to the other subscales. As expected, there are strong positive correlations between Self-Oriented Perfectionism and Personal Standards subscales, while Socially Prescribed Perfectionism is more closely related to the interpersonal subscales of Concerns over Mistakes, Doubts about Actions, Parental Expectations, and Parental Criticism (Frost, Heimberg, Holt, Mattia, \& Neubauer, 1993). Due to the moderate theoretical and empirical overlapping across the measures, both instruments are frequently used in psychological research depending on the fit with the researcher's purpose.

\section{Perfectionism and Self-discrepancies}

Unlike self-discrepancies, perfectionism does not imply that one is not meeting the standards established by themselves or by others, rather focusing on the magnitude and unrealistic characterization of the standards. While it is theorized that self- 
discrepancies are components of dispositional perfectionistic tendencies (Hankin et al., 1997; Hewitt \& Flett, 1991), there is significant overlap between the two conceptualizations, especially through the lens of Hewitt and Flett's HMPS. Conceptually, SOP appears to connect with Ideal self-guides due to the shared selfimposed standards, while SPP and Ought self-guides both refer to the perceived standards of others (Blatt, 1995). Theoretically, it may be hypothesized that SOP would be uniquely associated with depression (like A-I discrepancies) while SPP uniquely predicting anxiety (parallel with A-O discrepancies); while additional correlations will refute the unique predictive ability of perfectionism subscales on specific outcomes, results from Hankin et al. (1997) found A-I discrepancies and SOP to uniquely predict depression, A-O discrepancies to uniquely predict anxiety, and SPP to predict general emotional distress. Importantly, correlational matrices and additional explained variances by the variables support the differentiation between the constructs of perfectionism and self-discrepancies, suggesting that perfectionism may need to be controlled in order to fully observe the unique effect of self-discrepancies on psychological outcomes.

\section{Perfectionism's Connection to Religion}

As in perfectionistic individuals, religions place significant importance on achieving and maintaining high standards, often through emulating idealized figures or meeting expectations concerning specific beliefs and practices (Crosby, Bates, \& Twohig, 2011; Sorotzkin, 1998). While there is little overlapping research, increased religious activity was positively correlated with healthy perfectionism and high standards (Ashby \& Huffman, 1999), while unhealthy perfectionism has been found to be positively correlated with poorer spiritual functioning, disappointment with one's 
relationship with God (Thelander, 2002), and problematic extrinsic religiosity (Crosby et al., 2011). Due to the predisposition to emphasize religious practices over beliefs, Sorotzkin (1998) theorized that Jewish individuals, especially Orthodox Jews, may be primed to define their religious worth through comparisons against idealized or expected performance standards. These standards can come from one's own desire to meet their own religious and spiritual goals (e.g., requirements to obtain desired consequences), or they can be greatly affected by parental or community expectations; the latter behavioral guides may be predominate in highly religious families due to religion's influence in nearly all aspects of life. It is suggested that such a religious striving for perfection may feed extrinsic religiosity while depleting intrinsic motivation, theoretically contributing to lower mental and spiritual health (Worthington, Kurusu, McCullough, \& Sandage, 1996), as well as increased shame and guilt due to perceived failure to meet the standards (Tangney, 1995).

Similar to perfectionism's relationship with mental health, the adaptiveness and source of high religious standards, whether connected to self or social influences, may contribute to positive or negative religious outcomes such as spiritual well-being. In order to detect and observe the additional variance on mental and spiritual outcomes due specifically to religious self-discrepancies, the extent of the individual's overall perfectionism must be statistically controlled. The personal and interpersonal aspects of both perfectionism (as measured by Hewitt and Flett's [1991] scale) and religion may create unique relationships between Jewish self-discrepancies, orientation of perfectionism, and psychological variables (e.g., SOP, A-I discrepancies, depression, and spiritual well-being). 


\section{Spirituality}

The increased secularization, disillusionment with religious institutions, and empirical focus of the constructs within psychological research has led to divergent conceptualizations of religion and spirituality (George, Larson, Koenig, \& McCullough, 2000; Sheldrake, 1992). During the initial separation of the two constructs, religion was viewed as the fixed system of ideological and institutional expressions that are dictated by doctrinal and authoritarian principles, while spirituality was conceptualized as the idiographic, subjective, emotional, and non-systematic expressions of religious experiences (Hill \& Pargament, 2008; Koenig et al., 2001). However, a simplistic dichotomy erroneously hid the similarities between the two constructs, such as their focus on a connection with the sacred or divine, beliefs about the sacred, the effect of such beliefs on behaviors, participation in practices to reach a connection, and awareness of particular states of consciousness that may be religious or spiritual in nature (George et al., 2000; Hill et al., 2000; Pargament, 1999; Wuff, 1997).

Due to the overlap and the frequency of subjective spiritual experiences that occur within the context of religious beliefs and practices, most Americans do identify themselves as both religious and spiritual (Zinnbauer, Pargament, Cowell, Rye, \& Scott, 1997). The search for the sacred, the common denominator, is being experienced through traditional, non-traditional, and even non-religious (i.e., secular) contexts and identities. Thus, spirituality has been defined as "the paths people take in their efforts to find, conserve, and transform the sacred in their lives" (Zinnbauer et al., 1999, p. 909). Importantly, the sacred is not always represented as "God," but can be considered a higher power, ultimate reality, divine being, or a transcendental spirit (Larson, Swyers, \& 
McCullough, 1998; Sawatzky, Ratner, \& Chiu, 2005). Others have also included the existential search for purpose and meaning within the construct of spirituality, although such pursuits are expected to have an underlying relationship to sacredness (Larson, Swyers, \& McCullough, 1998; Thoresen, 1999). Understanding the effectiveness of the individual's pathway towards the experience of and connection to the sacred is an increasingly popular focus in psychological research that evaluates the role of religion and spirituality in our lives (Hill et al., 2000; Hill \& Pargament, 2008).

Religious involvement is strongly related to mental health outcomes (see Koenig et al., 2001 for a review), including satisfaction with life (Myers \& Diener, 1995), low to moderate effect size on lower depression (Koenig, Hays, George, \& Blazer, 1997; Cohen \&Koenig, 2003), lower anxiety (Koenig, Ford, George, Blazer, \& Meador, 1993), prevention of mental illness (Levin \& Chatters, 1998), and response to therapeutic treatment (Koenig, George, \& Peterson, 1998; Levin \& Chatters, 1998). The majority of religions support the maintenance of a healthy and idealized lifestyle that includes healthy behaviors and activities. George et al. (2000) summarized 10 domains of religion identified as possible mediators for the religion-mental health relationship, including membership, current and developmental history of participation, private religious and spiritual experiences, commitment to specific beliefs and values, motivation to regulate and reconcile relationships, religious and spiritual coping, and social support through the religious community. Meta-analyses have suggested that the last identified mediator, social support, is most responsible for religion's positive relationship on well-being (Argyle, 1999; Koenig et al., 2001). 
Where does spirituality belong in the religion-mental health relationship? As pointed out by Koenig et al. (2001), the most commonly used measurement of religiosity and spirituality tapped overall religious involvement through frequency of church attendance or denominational affiliation (Hill \& Pargament, 2008). As evidenced by the previous exploration into Jewish identity, frequency of attendance and denominational affiliation is a poor representation of the Jewish experience. In addition, the impetus on religious and spiritual practices rather than beliefs creates a different path towards the sacred as compared to the predominantly Christian research samples. In one study by Cohen (2002), congregational support and religious participation did positively affect life satisfaction, but the impact of spirituality, turning to God to cope with stress, and the above variables were significantly lower for Jewish participants as compared to Protestant and Catholic individuals.

Similar to psychological outcomes, spiritual well-being may be negatively affected by self-discrepancies within Jewish identity, especially due to Jewish experiences being a common domain for spiritual expression. Paloutzian and Ellison (1982) define spiritual well-being as the subjectively positive and healthy feelings of purpose, meaning, fulfillment, and joy gained through both religious and general existential realms. Considering Judaism's frequently reduced focus on God-focused dogmatic beliefs, the above researcher's Spiritual Well-Being Scale appears to be most appropriate to equally assess and differentiate spirituality from traditional (i.e., Religious) and non-traditional (i.e., Existential, cultural, and/or secular) paths. In addition, conceptual overlaps may show that discrepancies in Jewish identity on the Religious subscale may greatly influence an individual's Religious spiritual well-being, while 
discrepancies on the Cultural subscale may explain more variance in Existential spiritual well-being.

\section{Research Questions and Hypotheses}

The current research project will explore individually-defined conceptualizations of American Jewish identity across varying Jewish experiences and clarify its religious, cultural, and psychological effects. More specifically, does the perception of not being a "good enough Jew," as evidenced by self-discrepancies in one's Jewish identity, have negative psychological and spiritual consequences? The following hypotheses are designed to evaluate the research agenda:

1. The first hypothesis is that Jews across all denominations will report statistically significant Jewish self-discrepancies.

2. The second hypothesis is that Jews from more traditional denominations will report significantly smaller Jewish self-discrepancies, such that Orthodox Jews report the smallest discrepancies while secular Jews report the largest discrepancies.

3. The third hypothesis is that Religious, as compared to Cultural, self-discrepancies will explain more variance in overall Jewish self-discrepancies across all denominations.

4. The fourth hypothesis is that Jewish self-discrepancies will predict more symptoms of depression, anxiety, and stress, even after controlling for perfectionism. While the unique prediction hypothesis (i.e., A-I predicting depression and A-O predicting anxiety) will be tested, there does not appear to be enough empirical or theoretical support to suggest that specific Jewish self-discrepancies will influence only depression or anxiety. 
5. The fifth hypothesis is that Jewish self-discrepancies will predict poorer overall spiritual well-being.

6. The sixth hypothesis is that Jewish self-discrepancies are expected to be more detrimental to Existential, rather than Religious, spiritual well-being.

7. The seventh hypothesis is that the association between Jewish self-discrepancies and well-being will be moderated by Membership self-esteem, such that the effect of selfdiscrepancies on psychological and spiritual outcomes will be smaller for those reporting higher Membership self-esteem.

8. The eighth and final hypothesis is that the association between Jewish selfdiscrepancies and well-being will be moderated by the Importance of Judaism Identity to overall identity, such that the effects of self-discrepancies on psychological and spiritual outcomes will be larger for those reporting higher Importance to Identity. 


\section{METHOD}

\section{Sampling of Participants}

Participants will be widely recruited to obtain a representative community sample of American Jewish experiences. Minimum criteria for participation include being over the age of 18 and self-identifying as Jewish. Primary networks of recruitment include places of worship, academic organizations (e.g., Hillel, Birthright, Chabad), Jewish social groups (e.g., Brotherhood and Sisterhood, Jewish Community of Louisville, official Facebook groups affiliated with Jewish socialization), and internet newsletters and listservs connecting Jews of various backgrounds from around the country (e.g., National Jewish Federation, American Jewish Press). Letters to Rabbis and Presidents of local synagogues will be sent requesting assistance in distributing information about the study; due to the frequency of Judaism-related studies that recruit substantially lower number of Orthodox Jews, as well as the higher likelihood of obtaining larger numbers of nonOrthodox Jews through aforementioned networks, the synagogue recruitment will be essential in obtaining a significant Orthodox sample. Snowball sampling will be utilized, as participants will be asked to pass along information about the study to other qualified participants who may meet the inclusion criteria.

A power analysis is required to ensure that the sample size is sufficient to properly identify effects sizes within the analyses. The standard recommendation for necessary sample size in analyses utilizing structural equation modeling is ten 
observations for each parameter. The largest model to be explored includes 25 parameters, calling for 250 observations. Due to the separation of the sample into two separate samples based on the randomly assigned procedure (to be detailed later), the required sample size must be doubled, requiring a total of 500 participants to ensure sufficient power.

\section{Instruments}

American Jewish Identity Scale (AJIS; Friedlander et al., 2010). The AJIS is a 33-item self-report measure of the practices, behaviors, values and beliefs endorsed as part of the American Jewish experience. Previous scales of Jewish identity were unidimensional, making it difficult to identify the wide range of variations in Jewish identity; in response, the AJIS is the first such scale that contains separate Religious Identity (RI) and Cultural Identity (CI) subscales. The RI items inquire about adherence to religious laws, principles, and rituals across all levels of religious observance, including "I light candles on the Sabbath," "I ritually wash my hands before eating bread," and "I celebrate all Jewish holidays." In comparison, the CI scale probes for Jewish values, attitudes, behaviors, and traditions that are seen in both secular and observant individuals, including "It is important for me to date or marry a Jew," "I feel a strong connection to Israel," and "'Tikkun olam' ('healing the world') is a Jewish value that is important to me."

To determine the presence of religious self-discrepancies, participants will complete the AJIS twice, each time from a different perspective. Each participant will first complete the scale by rating their Actual Jewish experience, followed by being randomly assigned to complete the items from either the Ideal or Ought Jewish identity 
perspective. AJIS items are typically answered on a 4-point Likert scale (1=not at all true of me, $2=$ a little true of me, $3=$ fairly true of me, $4=$ very true of me). However, to better assess discrepancies within Jewish identity, the range of Likert scores will be expanded to seven items $(1=$ not at all true of me, $2=$ rarely true of $m e, 3=$ a little true of $m e, 4=$ sometimes true of me, $5=$ fairly true of me, $6=$ almost always/very true of me, $7=$ always true of me); when normative scores are not used for comparisons, changes in scale format do not significantly alter the characteristics of the data (Dawes, 2008).

Religious and cultural identity factor scores are analyzed independently rather than using aggregate scoring, allowing for the exploration of each factor's unique contribution to the dependent variables. The Religious and Cultural Identity subscales did result in a moderately high correlation of .78, though confirmatory factor analyses, convergent validity, and divergent validity evidence maintained the presence of two distinct subscales (Friedlander et al., 2010); during the development of the scale, Cronbach alphas were .95 (total AJIS), .93 (RI), and .88 (CI). The AJIS is a fairly new scale without any published replications to date, so a secondary purpose of this study will be to analyze the psychometrics of the scale. During its creation, RI scores properly differentiated between self-identified denominations, such that Orthodox Jews scored significantly higher than Conservative Jews, who scored significantly higher than Reform. In addition, as expected by their hypotheses based on previous literature on Jewish identity, CI was rated significantly higher than RI across all denominations, but there was a wider range of CI amongst those lowest in RI.

Procedure for measuring self-discrepancies. Self-discrepancies are identified by measuring the gap between an individual's Actual self and either their Ideal (own) or 
Ought (others') standards and expectations. Procedures similar to previous selfdiscrepancy studies will be followed, assessing each identity construct by using the nomothetic AJIS as the within-subject comparison measure rather than either an adjectives checklist or the idiographic Selves Questionnaire (Hardin \& Lakin, 2009; Higgins, Bond, Klein, \& Strauman, 1986; McDaniel \& Grice, 2008). Each participant will complete the AJIS from the perspective of their Actual self, being prompted to answer each item considering the beliefs, practices, and values they currently possess or maintain.

Due to concerns about questionnaire length and the ability for individuals to clearly differentiate between ideal and ought selves (Tangney, Niedenthal, Covert, \& Barlow, 1998; Watson, Bryan, \& Thrash, 2010), each participant will be randomly assigned to complete the AJIS again with either an Ideal or Ought self-perspective on their Jewish identity. Those completing the AJIS considering their Ideal Jewish identity will be given the following prompt, adapted from Petrocelli \& Smith, (2005):

You may have an Ideal Jewish identity that represents all the attributes of a Jewish life that you'd truly like to maintain. It's defined by the practices, traditions, and beliefs that you would ideally like to have. It's not necessary that you actually have these characteristics now, only that you believe you want to maintain these specific practices or beliefs. Please fill out the following items (this page only) as if you met the personal standards of your Ideal Jewish identity. 
Questions inquiring about the Ought Jewish identity perspective will be prompted with the following:

There may be a Jewish identity that you believe you ought to have, defined by the practices, traditions, and beliefs you believe you have the duty or obligation to maintain. These aspects of the Jewish life you ought to have may be influenced by your congregation, Rabbi, family, or overall understanding of Judaism. It's not necessary that you actually have these traits now, only that you or significant others believe you ought to have them. Please fill out the following items (this page only) as if you met the standards of a Jewish identity that you believe you ought to maintain.

Self-discrepancy scores for Jewish identity begins by averaging the Likert scores on the Religious Identity and Cultural identity subscales from each perspective. The ActualIdeal (A-I) and Actual-Ought (A-O) discrepancies are computed by subtracting the average Ideal or Ought scores from the Actual score. Because it is expected that reported Ideal and Ought Jewish identities will result in higher average scores than the Actual Jewish experience, the absolute value of the difference will be computed to ease interpretation of the size of the discrepancy.

Multidimensional Perfectionism Scale (MPS; Hewitt \& Flett, 1991). The Multidimensional Perfectionism Scale is a 45-item self-report measure tapping three distinct aspects of perfectionism. Self-oriented perfectionism (SOP) includes self-directed behaviors to set high standards and motivate oneself to achieve perfection (e.g., "One of my goals is to be perfect in everything I do" and "I must work to my full potential at all times"). Socially prescribed perfectionism (SPP) contains beliefs that others have 
excessively high standards for oneself and forms the basis of conditional acceptance (e.g., "My family expects me to be perfect" and "Those around me readily accept that I can make mistakes too" [reverse scored]). The third subscale (other-oriented perfectionism) measures one's unrealistic standards and expectations for other people' behaviors, but this subscale is not utilized for the purpose of this study. The 15 items for each subscale are scored on a Likert scale from 1 (strongly disagree) to 7 (strongly agree), with higher scores translating to a stronger presence of perfectionistic beliefs and behaviors.

Cronbach alphas have consistently been above .70, with SOP ranging from .86-.94 and SPP from .79-.97. In addition, the correlation between SOP and SPP is low to moderate, ranging from .19-.46 (Flett, Galfi-Pechenkov, Molnar, Hewitt, \& Goldstein, 2012; Hankin, Roberts, \& Gotlib, 1997; Hewitt \& Flett, 1991; Stoeber \& Childs, 2010; Stoeber, Otto, \& Dalbert, 2009).

As compared to other models of perfectionism, Hewitt and Flett's (1991) distinction between personal and social dimensions theoretically matches other variables of interest. Hankin, Roberts, and Gotlib (1997) found that self-discrepancies (i.e., A-I and A-O) and dimensions of perfectionism were weakly correlated, yet SOP appeared to be uniquely related to depressive symptoms while SPP related more to anxiety. Both perfectionism and self-discrepancies include self-standards, yet perfectionism does not inherently involve a discrepancy but rather the magnitude of those standards. So, while one may expect a strong ability for SOP to predict A-I discrepancies and SPP to predict A-O discrepancies due to conceptual overlap, more research is needed to determine the uniqueness and strength of the relationships. 
Socially prescribed perfectionism is more strongly associated with psychopathology, specifically anxiety, maladaptive coping, and negative affect (Stoeber $\&$ Childs, 2010). Similar to self-discrepancy theories, the link between SPP and anxiety has been found (Hewitt \& Flett, 1991; Saboonchi \& Lundh, 1997), but unique predictive abilities have not been confirmed; Flett et al. (2012) found that SPP, which was expected to be more closely linked to anxiety, explained more variance in depressive symptoms than SOP. While the unique predictability of perfectionism on self-discrepancies, anxiety, and depression has not been thoroughly examined, their influence on the presentation of such symptoms warrants inclusion within the model.

Collective Self-Esteem Scale (CSES; Luhtanen \& Crocker, 1992). The Collective Self-Esteem Scale is a 16-item measure of personal identity and esteem one feels towards their membership to the specific social group, e.g., ethnicity or religion. Four items make up each of the four subscales identified through factor analysis. Membership self-esteem (MSE) gauges the extent one feels like a worthy member of their ethnic, religious, or social group (e.g., "I am a worthy member of my ethnic group" and “I feel I don't have much to offer to my ethnic group)." Importance to Identity explores the centrality of the specific group membership to one's self-concept (e.g., "The ethnic group I belong to is an important reflection of who I am" and "Overall, my ethnicity has very little to do with how I feel about myself)." Private and public selfesteem assess the positive evaluation of one's own group and the perception of how other's perceive one's group, respectively; however, for the purposes of this research, these two subscales will not be administered. 
Items are scored on a 7-point Likert scale, ranging from strongly disagree to strongly agree, with particular items needing reverse scoring. Since the scale was originally designed for use in regards to ethnic groups, the phrase "my ethnic identity" will be changed to "my Jewish group" (Altman, 2010). Previous reports of internal consistency for CSES subscales have ranged from .66-.75 for MSE and .79-.84 for Importance to Identity (Bizman \& Yinon, 2004; Luhtanen \& Crocker, 1992). Luhtanen \& Crocker (1992) expected that more active members would score higher across all subscales of the CSES as individuals are motivated to positively view groups close to one's self-concept.

Spiritual Well-being Scale (SWBS; Paloutzian \& Ellison, 1982). The Spiritual Well-being Scale is a 20 -item instrument measuring overall spiritual health and need for transcendence. The scale is comprised of two subscales designed to tap distinct constructs: Religious Well-being (RWB) and Existential Well-being (EWB). The RWB assess the degree individuals report having a satisfying relationship with God, including items such as "I believe that God loves me and cares about me" and "I believe that God is impersonal and not interested in my daily situations." The EWB contains items pertaining to one's direction and satisfaction with life, specifically in relation to the self, community, and surroundings; sample EWB items include "I feel that life is full of conflict and happiness" and "I feel very fulfilled and satisfied with life." Completed using a 6-point Likert scale $(1=$ strongly disagree to $6=$ strongly agree $)$, subscale scores are calculated through summing the responses to the items, with higher scores translating to higher religious or existential spiritual well-being. 
Although the scale uses "God" within its RWB subscale, the SWBS was not designed specific to any religious or faith tradition, focusing more on psychological aspects of spiritualty rather than theological well-being (Boivin, Kirby, Underwood, \& Silva, 1999). While there have been concerns about ceiling effects within certain religious populations, Genia (2001) found that the SWBS was able to measure scores three standard deviations above the mean for Jewish respondents, as compared to 1.5 SD's above mean for Catholics and Protestants; a strength of the SWBS is its sensitivity for scores in the lower continuum and that it can be used in many different contexts and populations (Boivin et al., 1999). Internal consistencies have ranged from .82-.94 for RWB, .78-.86 for EWB, and .89-.94 for SWB, and test-retest reliabilities across samples from 1-10 weeks were all above .70 (Boivin et al., 1999; Kneipp, Kelly, \& Cyphers, 2009). This measurement of spiritual well-being was chosen for the purposes of this study due to its separation of spirituality constructs, offering the ability to explore the possibility of religious identity to uniquely predict religious well-being and cultural identity to uniquely predict existential well-being.

Hospital Anxiety and Depression Scale (Zigmond \& Snaith, 1983). The Hospital Anxiety and Depression Scale is a self-report measure containing 14 items rated on a 4-point Likert scale, with seven items assessing anxiety (e.g., "worrying thoughts go through my mind") and seven items assessing depression (e.g., "I feel as if I am slowed down"). Higher scores indicate increased levels of distress. Adequate reliability was reported through internal consistency scores of .83 for anxiety and .82 for depression (Bjelland, Dahl, Haug, \& Neckelmann, 2002). Scores from this sample reported Cronbach alphas of .81 for Anxiety and .76 for Depression. 
Demographic information. Participants will be asked to complete demographic items, including gender, age, ethnicity, geographic location, marital status, number of children, and yearly income. Additionally, participants will be asked to report their selfidentified Jewish denomination (i.e., Secular/non-practicing, Reform, Conservative, Orthodox, Hasidic, Reconstructionist, agnostic, atheist, or other).

\section{Procedure}

Recruitment flyers, e-mails, announcements, and listserv posts will include the title and purpose of the study, inclusion criteria, statements about anonymity and institutional approval, anticipated length of time, information about possible financial reward, and a website link that will contain the questionnaire. SurveyMonkey will be utilized to create and administer the survey, with possible participants being required to read and accept the terms of the informed consent and inclusion criteria before continuing on with the survey. All responses will be anonymous as no identifying information will be ascertained, and participants will be assured they can exit the survey at any time. Upon completion of the survey, participants will be given a link to another SurveyMonkey survey in which they can submit their e-mail address for a chance to win one of three $\$ 50$ Visa prepaid gift cards. Participants may also be able to inform the researcher they desire feedback on the results of the study.

Participants will be provided with contact information for the primary researcher and supervisor, the University of Louisville, and the Institutional Review Board for the University of Louisville if any questions, concerns, or complaints are to be reported. Participants will also be given contact information for a national crisis phone bank and 
additional mental health resources if they are currently experiencing distress due to either the survey content or extraneous influences.

Participants will complete the demographics questionnaire, the American Jewish Identity Scale twice from different perspectives, an abbreviated Multidimensional Perfectionism Scale, two subscales of the Collective Self-Esteem Scale, the Spiritual Well-Being Scale, and the Hospital Anxiety and Depression Scale, totaling 145 total items. It is expected to take approximately twenty minutes to complete.

\section{Proposed Statistical Analyses}

Two separate sets of analyses will be completed due to each participant only responding to the survey from only the Ideal or Ought perspective; attempting to combine A-I and A-O discrepancies in the same statistical tests would result in substantial missing data. Subsequent models depicting Jewish Self-Discrepancies will be analyzed twice from each specific discrepancy perspective. Randomization of participant into the two groups will be validated through ANOVAs across all independent, dependent, and demographic variables.

Analysis of the correlation matrix will identify the relational dynamics of the included variables and check for any concerns of multicollinearity. A one-tailed t-test will determine if overall Jewish self-discrepancies are significantly above zero (Hypothesis 1). The second hypothesis will be tested with a one-way Analysis of Variance (ANOVA), with denominations as the levels of the independent variable (i.e.,

secular, Reform, Conservative, and Orthodox) and overall Jewish self-discrepancy as the dependent variable. 
Structural equation modeling will be utilized to test hypotheses 3-8. The statistical significance and relative strength of the paths from Cultural and Religious selfdiscrepancies to overall Jewish self-discrepancies will test Hypothesis 3. Analysis of Hypothesis 4 will utilize the path model depicted in Figure 1, as Jewish self-discrepancies from either the Ideal or Ought perspective may predict Depression and Anxiety. Perfectionism is included as a correlated exogenous variable in order to parse out the effects of dispositional perfectionistic tendencies on Jewish self-discrepancies and mental well-being. In addition, the unique prediction hypothesis will be confirmed if only one of the pathways from the specific self-discrepancy remains within the model; for example, if the pathway from Actual-Ought discrepancies to Anxiety is significant while the pathway to Depression is not significant, the theoretical hypothesis will be confirmed.

The model illustrated in Figure 2 will test Hypothesis 5, observing the significance of the pathways from Jewish self-discrepancies to both subscales of Spiritual Well-Being. Hypothesis 6 will be explored by separating the latent variable of Jewish self-discrepancies into its components and observing the significance and relative strength of the pathways from Religious and Cultural self-discrepancies to Religious and Existential well-being.

The moderating variables included in Hypotheses 7 and 8 require the scores in Jewish self-discrepancies, Membership Self-esteem, and Importance to Identity will be statistically centered to properly create interaction variables to include within the analyses. Structural equation modeling will be utilized to test the possible moderating effects of Membership Self-esteem and Importance to Identity on the impact of Jewish self-discrepancies on the outcome variables; significant pathways from the interaction 
terms to the outcome variables will support the presence of a moderating effect and prompt additional post-hoc analyses.

Multiple global fit indices will be utilized to determine the overall fit of the theoretical models from each self-discrepancy perspective (Hu \& Bentler, 1999). Analyzed indices will include overall chi square test of model fit and p-value for test of good fit (both of which should be non-significant), the Root Mean Square Error of Approximation (RMSEA should be below .08), and the Comparative Fit Index (CFI greater than .90). However, more focus will be placed on statistical significance of individual pathways as opposed to global fit indices. Due to the multiple statistical comparisons throughout the eight hypotheses, a Bonferroni correction indicates an alpha of .006 to achieve statistical significance. 


\section{INTRODUCTION}

Judaism is a distinctive combination of religious, spiritual, cultural, and ethnic experiences that create an identity quite different than other religious groups. The common understanding of Judaism begins with its role as a religion: a set of shared practices, beliefs, laws, and values that influence relationships with oneself, others, the environment, and the transcendent (Koenig, McCullough, \& Larson, 2001). However, a strictly religious interpretation of Judaism ignores the sizable and growing population of American Jews that do not identify with the religious principles of their ancestors but still self-identify as Jewish (Klaff, 2006). In his exploration of Judaism within the multicultural revolution of psychology, Langman (1999) asserted that a purely religious approach towards defining Jewish identity was a misconception, devaluing the addition of Jewish identity as a religious group, a people, an ethnicity, a culture, and a civilization. Therefore, a thorough exploration of American Jewish identity must balance both religious and cultural factors.

Expanding on identity exploration, Rogers (1954) established a rich empirical foundation highlighting the presence of personal self-discrepancies based on expectations from oneself or one's external system. Self-discrepancies are created when one's Actual identity either does not match the personally-held desires of an Ideal identity (ActualIdeal, or A-I, discrepancy) or does not fulfill the perceived obligations of one's community that defines an Ought identity (Actual-Ought, or A-O, discrepancy). If religion is a significant aspect of most individuals' overall identity, then the failure to 
meet idiosyncratically perceived standards of Judaism, established by one's own desired identity or expectations from Judaic scripture and community, may play an important role in psychological and spiritual functioning. However, few empirical investigations have sought to identify self-perceived gaps within religious or ethnic identities and determine their impact on well-being; additionally, even fewer studies explore religion or ethnicity from a perspective generalizable to the current American Jewish demographic.

Continuing Schlosser's (2006) call for affirmative therapy with Jewish individuals, this study seeks to identify perceived self-discrepancies within Jewish identity and explore their impact on mental (i.e., depression and anxiety) and spiritual well-being.

\section{Judaism Identity}

The religion of Judaism is a monotheistic theology based on writings of the Torah (i.e., the first five books of Moses), the teachings of the Prophets, and the Writings of influential Rabbis; together, the literary foundation of Judaism is found within the TaNaKh, an anagram that represents the totality of the above writings. Overall, Judaic teachings and practices primarily focus on three responsibilities designed for personal, spiritual, and social growth: Teshuvah (repentance), Tefillah (prayer), and Tzedakah (charity). The traditions of Jewish culture often extend the religious experiences, focusing on the values, attitudes, behaviors, and community atmospheres that encompass Jewish lifestyles (Friedlander et al., 2010).

While individual Jewish experiences greatly vary in the breadth and consistency of upholding religious and cultural Jewish experiences, stricter adherence to specific religious practices successfully differentiated denominations (Friedlander et al., 2010). In order of most to least traditional, the common denominations are Hasidism, Orthodox, 
Conservative, Reform, and secular/humanist Judaism (oftentimes self-identifying as "Just Jewish"). While there are common patterns of observance specified by each denomination's religious and cultural expectations, individual differences in Jewish experiences influences how one may assess their current Jewish identity as well as the perceived success or failure in meeting specified expectations (Schlosser, 2006). The presence and size of Jewish self-discrepancies are idiosyncratically based on the extent one's actual Jewish identity does not meet expected participation in Judaic practices, beliefs, and values that are internalized and/or exemplified by their religiously affiliated community.

Judaism is also viewed as an ethnic identity stemming from one's membership to a social group, including the knowledge, values, and emotional significance attached to one's belonging to that group (Tajfel, 1981). Amongst Jews, there appears to be a positive relationship between cultural identification and religious observance, with primary attention on traditions and practices that contribute to the sense of community and the transmission of identity onto one's children. As one participant from Altman et al. (2010) stated: "You don't need to be very religious to be considered Jewish; there's also that importance of community, appreciation of your ethnicity, and being with Jewish people" (p. 166).

Unlike previous generations that resisted secularization, contemporary American Jews are individually defining their own Jewishness based on both religious and cultural foundations, a construct Cohen and Eisen (2000) termed the "sovereign self." Idiosyncratic identity development, rather than relying on expectations or normative behaviors, has significantly altered both the conceptualization and measurement of 
Jewish identity and experiences. The original exploration of Jewish identity sought to measure the "Jewishness" of the American Jewry, as if there was a traditional Jewish "yardstick" that awarded inches for years of early Jewish education, synagogue attendance, participation in extracurricular Jewish activities, and strict observance of Jewish laws and responsibilities (Charme, Horowitz, Hyman, \& Kress, 2008; Horowitz, 1999).

The normative operationalization of American Jewishness became problematic as successive generations moved towards secularization, coinciding with reduced religious practice and ethnic solidarity within Jewish communities. If the yardstick of Jewish identity remained transfixed in the Orthodoxy of Judaism, then the majority of American Jews would develop discrepancies by falling short of the yardstick, categorized as "less than Ideal" or not being a "good enough Jew" (Horowitz, 1999). While this contention may be accepted by some individuals from more fundamental denominations, such a conceptualization of the American Jewish experience would be disingenuous and rejecting through psychological and sociological lenses (Charme et al., 2008; Horowitz, 2002; Schlosser, 2006).

The exploration of Jewish identity shifted focus from externally supported facts of religiousness towards the internal, personal, and subjective experiences of one's worldview (Horowitz, 1999). As opposed to the yardstick proposal, idiosyncratic development of Jewish identity allows for myriad combinations of beliefs, practices, values, and community involvement without requiring the category of "less than Ideal" Jewish self-identities. The strength, content, and consistency of Jewish identity can fluctuate, change, ebb, and flow in response to personal and environmental contexts and 
life events, but the underlying Jewish foundation remains. Despite the personal control in defining Jewish identity, the influence of the normative yardstick can not be forgotten. While more traditional denominations place great significance on properly "measuring up," Jews from all religious and cultural engagements may be cognizant of the Judaic expectations, obligations, and duties held by the religious community (e.g., synagogue, Rabbi, and family traditions). For the purposes of this study, the American Jewish Identity Scale (AJIS; Friedlander et al., 2010) was chosen as the appropriate instrument for participants to idiosyncratically define both their religious and cultural Jewish identities in a way consistent with the aforementioned trends and shifts in Jewish experiences.

Regardless of denomination, questions remain as to the extent to which American Jews measure themselves against a normative yardstick. Do Jews internalize a personally relevant yardstick that leads to a discrepancy between their current and Ideal Jewish identity? Do denominational or Judaic community yardsticks highlight discrepancies between current and expected (later referred to as "Ought") Jewish identities when salient gaps are perceived? Do these discrepancies differ between denominations and impact mental or spiritual well-being? These questions form the crux of the current research agenda.

\section{Judaism and Mental Health}

Religious beliefs and practices have consistently been linked with lower levels of anxiety and depression while being positively related to life satisfaction and well-being (see Bonelli \& Koenig, 2013 for review). However, the vast majority of research within this field has either focused predominately on Christian samples or explored the 
relationships through a Christian conceptualization of religiosity. Cohen (2002) already demonstrated that religious beliefs have little impact on life satisfaction of Jews, but whether this finding generalizes to mental health outcomes remains to be determined.

Judaic denominations appear to interact with the salience of religious beliefs in their effects on mental health. After controlling for religious practices, lower levels of belief in the benevolence of God predicted additional anxiety and depression for Orthodox Jews and Protestant Christians but not for non-Orthodox Jews (Rosmarin et al., 2009b). Amongst responses from Orthodox Jews, religious practices and beliefs accounted for $19 \%$ of the variance in depression and $12 \%$ in anxiety while higher religiosity predicted lower levels of both symptoms. This result illustrates the power of religiosity and connectedness to God as a protective power against distress for the more traditional Jews (Abromowitz, Huppert, Cohen, Tolin, \& Cahill, 2002).

Jewish ethnic identity tends to be highly correlated with positive in-group attitudes, perceived salience of Jewish identity (Goodman, 2002), religious participation (Weisskirch, 2004), and global spirituality (Kakhnovets \& Wolf, 2011). However, the limited empirical evidence has found only weak or insignificant correlations between Jewish ethnic identity and psychological well-being constructs, such as anxiety and depression (Goodman, 2002; Kakhnovets \& Wolf, 2011). Similar to ethnic identity, Jewish self-discrepancies may only be meaningful psychological variables if Jewish identity is salient and central to overall identity (Phinney, 1996). Two particular areas of ethnic identity that may be relevant to Judaism include membership self-esteem and importance to identity self-esteem (Luhtanen \& Crocker, 1992). Membership self-esteem (MSE) assesses the extent one feels like a worthy member of their ethnic, religious, or 
social group; hypothetically, an individual that recognizes Jewish self-discrepancies while still experiencing high MSE may be buffered from negative psychological and spiritual consequences. Additionally, importance to identity self-esteem (IISE) measures the perceived centrality of the particular group membership to one's overall identity. Jews with low IISE may show a softened relationship between Jewish self-discrepancies and outcome variables due to the more distal role of Judaism in overall identity. As low MSE and high IISE may also impact the relationship between Jewish self-discrepancies and well-being, both ethnic identity variables will be explored as moderating variables.

\section{Self-Discrepancy Theory}

Rogers (1951) theorized that a discrepancy between the way one actually sees oneself (Actual self) and the 'I' or 'me' that one would truly like to be (Ideal self) is the primary determinate of negative psychological states. Expanding self-discrepancy theory, Higgins (1987) theorized the existence of three basic domains of the self, representing the attributes the person perceives from varying viewpoints. While the Actual and Ideal selves maintain Rogers' conceptualization, Higgins identified the "Ought self" as the attributes one perceives they should or ought to possess, specifically related to a sense of duty, obligation, or responsibility (Higgins, Bond, Klein, \& Strauman, 1986). A central tenant of Higgins' (1987) theory is that people are motivated to eliminate the discrepancy, seeking congruency between one's current identity and perceived ideal and ought yardsticks. Consistent with Rogers' theory, larger perceived discrepancies lead to more emotional and cognitive discomfort. However, Higgins adds to the literature by conjecturing that specific self-discrepancies will uniquely predict different negative psychological states. 
The perception that the actual self is failing to maintain the attributes and standards of the ideal self often leads to dejection-related emotions, including sadness, disappointment, and depression (Higgins et al., 1986a; McDaniel \& Grice, 2008). The Actual-Ideal (A-I) discrepancy highlights the failure to obtain positive outcomes in the search for the ideal self, including the unfulfilled goals and desires of the individual. On the other hand, the perceived presence of negative outcomes is theorized to coincide with the belief that one's actual self is not fulfilling the sense of duty, obligation, or responsibility held by the standards of the ought self. The Actual-Ought (A-O) discrepancy is expected to predict anxiety-related symptoms (e.g., guilt, shame, fear) due to the sense of punishment that coincides with failure to live up to the expectations and standards of others (Higgins et al., 1986b; Large \& Marcussen, 2000). The strength of the emotional consequence is affected not only by the magnitude of the discrepancy but also by the accessibility or awareness of the discrepancy. Identity facets that are highly salient to one's self-concept, such as Jewish identity, will be more sensitive to emotional reactions due to incongruences (Large \& Marcussen, 2000).

\section{Empirical Support for Self-Discrepancy Theory}

Rogers and colleagues first found that reduced discrepancies coincided with lower anxiety and depression within the context of client-centered (Barrett-Lennard, 1962; Rogers \& Dymond, 1954; Meyer, 1981) and cognitive-behavioral or interpersonal therapies (Strauman et al., 2001). Moretti and Higgins (1990) found the identification and exploration of A-I discrepancies helped explain the presence of low self-esteem. Clinically, individuals diagnosed with depression have larger A-I discrepancies than nondepressed participants, while those with anxiety-related diagnoses have larger A-O 
discrepancies than non-anxious participants (Higgins et al., 1986b). Empirical explorations have found self-discrepancies to be predictive of depression (Strauman et al., 2001; Tangney, Niedenthal, Covert, \& Barlow, 1998), anxiety (Hart, Field, Garfinkle, \& Singer, 1997), or both mental health constructs (Ozgul, Heubeck, Ward, \& Wilkinson, 2003; Scott \& O’Hara, 1993; Phillips \& Silvia, 2010).

One concern elucidated through self-discrepancy research suggests that the participants may have difficulty drawing strong distinctions between the Ideal and Ought selves due to their theoretically close proximity and shared developmental relationship (Ozgul et al., 2003; Tangney et al., 1998). In fact, Tangney et al. (1998) reported that the most frequently asked question during the data collection was "What's the difference between Ideal and Ought?" This overlap is evident in significantly high correlations between the A-I and A-O discrepancies. While Higgins (1987) reported intercorrelation ranges from $.53-.76$, more recent studies have reported intercorrelations ranging from $.67-.80$ (Tangney et al., 2008) to even .92 (Hart et al., 1997). Some have argued that these high intercorrelations suggest that only a single discrepancy is being measured (Gramzow, Sedikides, Panter, \& Insko, 2000; Tangney et al., 1998), while others continue to find evidence for two distinct discrepancies (Phillips \& Silvia, 2010; Watson et al., 2010). To appropriately address this concern, participants were randomly assigned to either the Ideal or Ought condition when completing the survey protocol.

As it is theorized that self-discrepancies may be components of dispositional perfectionistic tendencies (Hankin, Roberts, \& Gotlib, 1997; Hewitt \& Flett, 1991), perfectionism will be controlled in order to fully observe the unique effect of Jewish selfdiscrepancies on psychological outcomes. Perfectionism is positively associated with 
depression (Enns \& Cox, 1999; Flett, Hewitt, Blankstein, \& O’Brien, 1991; Hewitt \& Flett, 1991a; Hewitt, Flett, \& Ediger, 1996; Wyatt \& Gilbert, 1998), negative affect (Molnar, Reker, Culp, Sadava, \& DeCourville, 2006), and maintenance of anxiety disorders (Antony, Purdon, Huta, \& Swinson, 1998), while being negatively associated with subjective well-being and satisfaction with life (Bartsch, 2007; Molnar et al., 2006; Saboonchi \& Lundh, 2003).

\section{Jewish Identity and Self-discrepancies}

A primary purpose of this study is to determine if American Jews identify discrepancies between their Actual, Ideal, and Ought Jewish identities. Ideal and Ought Jewish perspectives are prevalent throughout the Jewish community (Altman et al., 2010) and may be impactful at the individual level, although the identification and importance of these perspectives may be influenced by the centrality of one's Jewish identity to overall self-concept. Discrepancies between the Actual and either the Ideal or Ought domains of Jewish identity would theoretically contribute to depression and anxiety, and this study will also explore whether religious self-discrepancies also negatively impact spiritual well-being.

The self-discrepancy literature shows a nearly complete exclusion of religious or spiritual identity, including studies that have involved Jewish participants. Lilliston and Klein (1991) examined overall self-discrepancies to coping with distress through religion, finding that A-O discrepancies were positively associated with anxiety while A-I discrepancies were positively related to depression. They also found that individuals with higher A-O discrepancies were more likely to seek practices and beliefs related to their religious identity after a personal crisis, pursuing steps to bring the actual religious 
identity closer to the ought religious identity. Connections to religious or ethnic identity can be made through the few studies that have shown the effects of group identification discrepancies on agitation and dejection-related emotions (Bizman \& Yinon, 2004; Petrocelli \& Smith, 2005). While these results provide evidence for a connection between self-discrepancies and religious practices and participation, the role of specifically religious self-discrepancies remains unclear.

The only other study examining self-discrepancy and religious constructs was an unpublished Master's thesis, within which A-I religious discrepancies were related to negative affect for Christians who identified as more influenced by their own expectations (low self-monitors; Parker, 2004). For the purposes of this study, it is encouraging to note that the Christian sample from the above thesis did identify significant religious discrepancies from the Ideal and Ought perspectives. As the generalizability of results from Christian samples to Jewish populations has increasingly become dubious, an exploration of self-discrepancies utilizing a Judaic-specific scale is necessary to more appropriately understand the implications of self-discrepancies on well-being.

Similar to psychological outcomes, spiritual well-being may be negatively affected by self-discrepancies within Jewish identity. Paloutzian and Ellison (1982) defined spiritual well-being as the subjectively positive and healthy feelings of purpose, meaning, fulfillment, and joy gained through both religious and general existential realms. Considering Judaism's frequently reduced focus on God-focused dogmatic beliefs (Cohen, Siegel, \& Rozin, 2003), the above researcher's Spiritual Well-Being Scale appears to be most appropriate to equally assess and differentiate spirituality from 
traditional (i.e., Religious) and non-traditional (i.e., Existential, cultural, and/or secular) paths. In addition, conceptual overlaps may show that discrepancies in Jewish identity on the Religious subscale may greatly influence an individual's religious spiritual wellbeing, while discrepancies on the Cultural subscale may explain more variance in Existential spiritual well-being.

\section{Research Questions and Hypotheses}

The current research project will explore whether the perception of not being a "good enough Jew," as evidenced by self-discrepancies in one's Jewish identity, have negative psychological and spiritual consequences. The following hypotheses are designed to evaluate this research agenda:

H1: Jews across all denominations will report statistically significant Jewish selfdiscrepancies.

H2: Jews from more traditional denominations will report significantly smaller Jewish self-discrepancies, such that Orthodox Jews will report the smallest discrepancies while secular Jews will report the largest discrepancies.

H3: Jewish self-discrepancies will predict higher ratings of depression and anxiety after controlling for perfectionism.

H4: Jewish self-discrepancies will predict poorer overall spiritual well-being.

H5: The association between Jewish self-discrepancies and well-being will be moderated by Membership Self-esteem, such that the effect of self-discrepancies on psychological and spiritual outcomes will be smaller for those reporting higher Membership Selfesteem. 
H6: The association between Jewish self-discrepancies and well-being will be moderated by Judaism's Importance of Identity to overall identity, such that the effects of selfdiscrepancies on psychological and spiritual outcomes will be larger for those reporting higher Importance to Identity. 


\section{METHOD}

\section{Participants}

A large sample $(\mathrm{N}=970)$ of self-identified American Jewish adults responded to an invitation to participate in a web-based survey. Participants were recruited through snowball sampling and direct invitations delivered (with clergy or administrative permission) to e-mail listservs belonging to religious, cultural, and/or spiritual Jewish communities. A total of 128 individuals were removed due to incorrect answers on the imbedded attention-check questions $(\mathrm{N}=81)$ or for missing greater than $10 \%$ of responses $(\mathrm{N}=47)$. The final sample size $(\mathrm{N}=829)$ were randomly assigned to the Actual-Ideal (A-I; $\mathrm{N}=419)$ and Actual-Ought $(\mathrm{A}-\mathrm{O} ; \mathrm{N}=410)$ samples. There were no significant differences $(p>.05)$ between the two samples across the demographic categories or Jewish identity scores.

The full sample was comprised of $71.8 \%$ women and $27.7 \%$ men aged $18-93$ years old $(M=53.18, S D=16.03)$. Most participants self-identified as of European descent (94.2\%), married (65.3\%), and have an overall household income above $\$ 75,000$ (63.2\%). While regions from around the United States were represented, the majority of participants reside in the Eastern United States (62.5\%). The demographic make-up of this sample appears similar to the samples studied by the original AJIS studies (Friedlander et al., 2010).

Participants were asked to self-identify their Jewish denominational affiliation and were later coded into their respective categories. Overall, 36.7\% identified as Reform 
$(\mathrm{N}=304), 25.7 \%$ Conservative $(\mathrm{N}=213), 8.0 \%$ Orthodox $(\mathrm{N}=68), 5.7 \%$

Reconstructionist (N=47), 13.0\% Secular/Humanist, 9.7\% Atheist/Agnostic, and 1.2\%

Other. Post-hoc analyses showed non-significant differences between the latter three categories regarding Jewish identity, leading to the creation of a "Just Jewish" category $(\mathrm{N}=197)$ to represent non-denominational Jewish individuals. The sample size for Reconstructionist Jews was not large enough for independent analyses or group comparisons but such responses were retained in the overall sample.

\section{Instruments}

American Jewish Identity Scale (AJIS; Friedlander et al., 2010). The AJIS is a 33-item self-report measure of the practices, behaviors, values and beliefs endorsed as part of the American Jewish experience. The AJIS contains separate Religious Identity (RI) and Cultural Identity (CI) subscales. The RI items inquire about adherence to religious laws, principles, and rituals across all levels of religious observance, including "I light candles on the Sabbath," "I ritually wash my hands before eating bread," and "I celebrate all Jewish holidays." In comparison, the CI scale probes for Jewish values, attitudes, behaviors, and traditions that are seen in both secular and observant individuals, including "It is important for me to date or marry a Jew," "I feel a strong connection to Israel," and "'Tikkun olam' ('healing the world') is a Jewish value that is important to me."

To determine the presence of religious self-discrepancies, participants completed the AJIS twice from two different perspectives during the same time frame. Each participant first completed the scale by rating their Actual Jewish experience, followed by being randomly assigned to complete the items from either the Ideal or Ought Jewish 
identity perspective. Random assignment into two samples reduced concerns about questionnaire length and the ability for individuals to clearly differentiate between Ideal and Ought selves (Tangney, Niedenthal, Covert, \& Barlow, 1998; Watson, Bryan, \& Thrash, 2010). AJIS items are typically answered on a 4-point Likert scale. However, to better assess discrepancies within Jewish identity, the range of Likert scores was expanded to seven $(1=$ not at all true of me, $2=$ rarely true of me, $3=$ a little true of me, $4=$ sometimes true of me, $5=$ fairly true of me, $6=$ almost always/very true of me, $7=$ always true of me); when normative scores are not used for comparisons, changes in scale format do not significantly alter the characteristics of the data (Dawes, 2008).

Religious and Cultural Identity factor scores were analyzed independently rather than using aggregate scoring, allowing for the exploration of each factor's unique contribution to the dependent variables. During the development of the scale, the Religious and Cultural Identity subscales resulted in a moderately high intercorrelation of $r=.78$, though confirmatory factor analyses, convergent validity, and divergent validity evidence maintained the presence of two distinct subscales (Friedlander et al., 2010). RI scores properly differentiated between self-identified denominations, such that Reform Jews scored significantly lower than Conservative Jews, who scored significantly lower than Orthodox Jews. In addition, CI was rated significantly higher than RI across all denominations, but there was a wider range of $\mathrm{CI}$ amongst those lowest in RI, meaning that Cultural Identity scores do not differentiate denominations in a similar fashion as Religious Identity scores. Within the current study, the intercorrelation between the subscales was found to be more moderate at $r=.63$ and Cronbach alphas were $\alpha=.94$ (RI) and $\alpha=.83(\mathrm{CI})$. 
Procedure for measuring self-discrepancies. Self-discrepancies are identified by measuring the gap between an individual's Actual self and either their Ideal (own) or Ought (others') standards and expectations. First, each participant completed the AJIS from the perspective of their Actual self, being prompted to answer each item considering the beliefs, practices, and values they currently possess or maintain. Second, each participant was randomly assigned to complete the AJIS a second time from either the Ideal or Ought perspective.

Those completing the AJIS considering their Ideal Jewish identity were given the following prompt, adapted from Petrocelli and Smith, (2005):

You may have an Ideal Jewish identity that represents all the attributes of a Jewish life that you'd truly like to maintain. It is defined by the practices, traditions, and beliefs that you would ideally like to have. It is not necessary that you actually have these characteristics now, only that you believe you want to maintain these specific practices or beliefs. Please fill out the following items (this page only) as if you met the personal standards of your Ideal Jewish identity.

Questions inquiring about the Ought Jewish identity perspective were prompted with the following:

There may be a Jewish identity that you believe you ought to have, defined by the practices, traditions, and beliefs you believe you have the duty or obligation to maintain. These aspects of the Jewish life you ought to have may be influenced by your congregation, Rabbi, family, or overall understanding of Judaism. It is not necessary that you actually have these traits now, only that you or significant others believe you ought to have them. Please fill out the following items (this page only) 
as if you met the standards of a Jewish identity that you believe you ought to maintain.

Self-discrepancy scoring of Jewish identity begins by averaging the Likert scores on the Religious Identity and Cultural Identity subscales from each perspective. The ActualIdeal (A-I) and Actual-Ought (A-O) discrepancies are computed by subtracting the Actual score from the Ideal or Ought score.

Spiritual Well-being Scale (Paloutzian \& Ellison, 1982). The Spiritual Wellbeing Scale (SWBS) is a 20 -item instrument measuring overall spiritual health and need for transcendence. The scale is comprised of two subscales: Religious Well-being (RWB) and Existential Well-being (EWB). RWB assesses the degree individuals report having a satisfying relationship with God (e.g., "I believe that God loves me and cares about me"). EWB contains items pertaining to one's direction and satisfaction with life, specifically in relation to the self, community, and surroundings (e.g., "I feel a sense of well-being about the direction my life is headed in"). Completed using a 6-point Likert scale ( $1=$ strongly disagree to $6=$ strongly agree), subscale scores are calculated through summing the responses to the items, with higher scores translating to higher religious or existential spiritual well-being. The SWBS has demonstrated appropriate convergent and discriminant validity (Slater, Hall, \& Edwards, 2001), including a reduced presence of a ceiling effect with Jewish samples (Genia Cronbach alphas for this analysis were $\alpha=.96$ for RWB and $\alpha=.87$ for EWB.

Hospital Anxiety and Depression Scale (Zigmond \& Snaith, 1983). The Hospital Anxiety and Depression Scale is a self-report measure containing 14 items rated on a 4-point Likert scale, with seven items assessing anxiety (e.g., "worrying thoughts go 
through my mind") and seven items assessing depression (e.g., "I feel as if I am slowed down"). Higher scores indicate larger levels of distress and previous clinical application reported strong concurrent validity with the appropriate diagnoses (Bjelland, Dahl, Haug, \& Neckelmann, 2002). Scores from this sample reported Cronbach alphas of $\alpha=.81$ for Anxiety and $\alpha=.76$ for Depression.

Multidimensional Perfectionism Scale (Hewitt \& Flett, 1991). The Multidimensional Perfectionism Scale is a 45-item self-report measure tapping three distinct aspects of perfectionism. Self-oriented perfectionism (SOP) includes self-directed behaviors to set high standards and motivate oneself to achieve perfection (e.g., "One of my goals is to be perfect in everything I do"). Socially prescribed perfectionism (SPP) contains beliefs that others have excessively high standards for oneself and forms the basis of conditional acceptance (e.g., "My family expects me to be perfect"). The 15 items for each subscale are scored on a Likert scale from 1 (strongly disagree) to 7 (strongly agree), with higher scores translating to a stronger presence of perfectionistic beliefs and behaviors. Higher scores on this perfectionism scale were positively correlated to both depression and anxiety (Hewitt \& Flett, 1991; Stoeber \& Childs, 2010). Cronbach alphas for this sample were reported as $\alpha=.92$ for SOP and $\alpha=.87$ for SPP.

Collective Self-Esteem Scale (CSES; Luhtanen \& Crocker, 1992). The Collective Self-Esteem Scale is a 16-item measure of personal identity and esteem one feels towards their membership to the specific social group, e.g., ethnicity or religion. Four items make up each of the four subscales identified through factor analysis. Membership self-esteem (MSE) gauges the extent one feels like a worthy member of their ethnic, religious, or social group (e.g., "I am a worthy member of my ethnic 
group"). Importance to Identity explores the centrality of the specific group membership to one's self-concept (e.g., "The ethnic group I belong to is an important reflection of who I am"). Items are scored on a 7-point Likert scale, and since the scale was originally designed for use in regards to ethnic groups, the phrase "my ethnic identity" was changed to "my Jewish group" (Altman, 2010). For this sample, Cronbach alphas were reported as $\alpha=.81$ for MSE and $\alpha=.68$ for Importance to Identity. 


\section{RESULTS}

\section{Preliminary Analyses}

A review of the correlation matrix (Table 1) does not provide evidence for problematic divergent validity among the measured constructs. One-way ANOVAs found no significant differences between the Ideal and Ought conditions: Age $(F(1,827)=.56, p=$ $.453)$, gender $(F(1,827)=.37, p=.545)$, ethnicity $(F(1,827)=.02, p=.904)$, geography $(F(1,827)=.00, p=.960)$, income $(F(1,827)=.13, p=.720)$ and marital status $(F(1$, $827)=.04, p=.834)$. In addition, there were no significant group differences for total AJIS scores $(F(1,827)=.10, p=.754)$, including Religious Identity $(F(1,827)=.07, p=$ $.795)$ and Cultural Identity $(F(1,827)=1.51, p=.220)$. Overall, there is sufficient evidence to support random assignment without significant differences between the two group samples.

American Jewish Identity among Denominations. The American Jewish Identity Scale (Friedlander et al., 2010) was designed to assess cultural and religious identification across Jewish denominations. To further measure the construct validity of the AJIS, oneway ANOVAs were utilized to determine group differences in both religious and cultural identification as one's Jewish affiliation becomes more traditionally defined.

As anticipated, there were significant group differences in Religious $(F(4,824)=$ 247.37, $p<.001)$ and Cultural $(F(4,824)=42.38, p<.001)$ Identities. Post-hoc analyses revealed nearly all group differences to be significant at the $p<.001$ level, with group 
means expectedly increasing along the continuum of Just Jewish, Reform, Conservative, and Orthodox affiliations (refer to Table 2).

\section{Primary Analyses}

Before exploring the impact of one's perception of not being a "good enough Jew," the presence of Jewish self-discrepancies must be confirmed (hypothesis 1). Discrepancies from both the conditions confirm this hypothesis (A-I: $M=.66, S D=.70$, $t(418)=19.33, p<.001, d=.58 ; \mathrm{A}-\mathrm{O}: M=.68, S D=.84, t(409)=16.20, p<.001, d=$ .58 ; refer to Table 3 for further results).

Hypothesis 2 expected participants from more traditional denominations to report significantly smaller A-I and A-O self-discrepancies than less traditional affiliations. To test this hypothesis, one-way ANOVAs found differences in A-I total discrepancies between denominations $(F(4,414)=11.18, p<.001)$. Post-hoc analyses indicated that there was a non-significant difference in total A-I discrepancy between $\operatorname{Reform}(M=.87$, $S D=.74)$ and Conservative $(M=.75, S D=.62, p=1.00)$ Jews while both denominations had significantly larger discrepancies than the Orthodox denomination $(M=.37, S D=$ $.68, p<.05$ for both differences). Amongst the Jewish denominations, there is a clear trend of smaller A-I discrepancies as one's identified denomination becomes more traditional, confirming the second hypothesis for the Ideal sample. However, there was no significant difference between the Orthodox and Just Jewish $(M=.38, S D=.70, p=$ 1.00) samples.

Jewish denominations differed on reported Actual-Ought discrepancies as well $(F(4,405)=6.25, p<.001)$. A similar trend of lower Actual-Ought discrepancies among more traditional denominations was observed, although the differences in mean 
discrepancy scores between Reform $(M=.80, S D=.79)$, Conservative $(M=.79, S D=$ $.77)$, and Orthodox $(M=.51, S D=.75)$ were not significant $(p>.85$ for differences among these three denominations). The Just Jewish A-O discrepancy $(M=.35, S D=.95)$ mean score was significantly less $(p<.001)$ than Reform and Conservative mean scores but not significantly different $(p=1.00)$ than the Orthodox scores. The lower A-O discrepancy among the Orthodox Jews also supports hypothesis 2, although results involving the Orthodox sample should be interpreted cautiously due to its smaller sample size ( $\mathrm{N}$ of 39 and 29 in Ideal and Ought samples, respectively).

Analyses to identify the separate contributions of Religious and Cultural discrepancies towards overall Jewish self-discrepancies were explored to gain insight into the source of the gaps. A linear regression showed that Religious A-I discrepancies $(M=$ $.84, S D=.91, \beta=.713)$ contributed more to the variance of A-I discrepancies than Cultural A-I discrepancies $(M=.45 ; S D=.59 ; \beta=.383)$. A similar regression for the Actual-Ought discrepancy illustrated similar results, with Religious A-O discrepancies $(M=.95, S D=1.07, \beta=.695)$ showing to be the larger contributor than Cultural A-O discrepancies $(M=.35, S D=.74, \beta=.399)$. Religious discrepancies explained more of the overall Jewish discrepancies as compared to Cultural discrepancies within both samples.

Hypotheses 3 through 6 were tested using Baron and Kenny's (1986) two-step structural equation modeling process. First, a confirmatory factor analysis was conducted for the measurement models and theoretically-consistent specification were applied to obtain adequate model fit. Next, the structural path model is analyzed for model fit and further re-specifications consistent with the statistical significance of the pathway are 
completed to develop the final, revised model. Religious and Cultural discrepancies were maintained as separate observed variables as opposed to creating one latent variable as a significant decrease in model fit (as measured by AIC statistics) was observed between competing models.

Hypothesis 3 suggested that larger Religious and Cultural Jewish selfdiscrepancies would predict higher anxiety and depressive symptoms. Starting with Ideal Self-Discrepancies, a respecified measurement model that controls for perfectionism (shown in Figure 3) demonstrated good fit $(\mathrm{df}=423, p<.001, \mathrm{C} / \mathrm{min}=2.049 ; \mathrm{CFI}=$ .918 ; RMSEA $=.050(90 \%$ CI .045-.055), pclose $=.481)$. Hair, Black, Babin, and Anderson (2010) suggest that CFI scores above .90 can be indicative of good fit for analyses with large sample sizes (i.e., greater than 200). The structural path model reported non-significant direct effects of Cultural A-I discrepancies on both anxiety and depression. After respecifying the model to remove those pathways, the relationship of Religious A-I discrepancy remained significant for both anxiety $(\beta=.132, \mathrm{p}=.007)$ and depression $(\beta=.151, \mathrm{p}=.004)$. The A-I model explained $33.0 \%$ of the variance in anxiety and $21.0 \%$ of the variance in depression. Even though the correlation between Cultural and Religious self-discrepancies was $r=.631$, only Religious A-I discrepancies positively affected depression and anxiety.

Next, the relationship of Actual-Ought discrepancies on mental well-being while controlling for perfectionism was analyzed. A respecified measurement model demonstrated good fit $(\mathrm{df}=338, p<.001, \mathrm{C} / \mathrm{min}=2.048 ; \mathrm{CFI}=.924 ; \mathrm{RMSEA}=.051$ $(90 \%$ CI .045-.056), pclose $=.418)$. The correlation between Religious and Cultural A-O discrepancies was $r=.644$. In contrast to the A-I model, the A-O Religious discrepancies 
did not result in significant impacts on depression and anxiety. Cultural A-O discrepancies demonstrated significant positive relationships with both anxiety $(\beta=.124$, $p=.014)$ and depression $(\beta=.144, p=.007)$. The A-O model (shown in Figure 4) explained $44.5 \%$ of the variance in anxiety and $16.1 \%$ of the variance in depression. Hypothesis 4 predicted that religious and cultural discrepancies would have a negative effect on spiritual well-being. First, the A-I model (see Figure 5) was tested and demonstrated adequate model fit $(\mathrm{df}=124, p<.001, \mathrm{C} / \mathrm{min}=2.903 ; \mathrm{CFI}=.959$; RMSEA $=.067$ (90\% CI .059-.076), pclose $<.001)$. However, the only path that remained significant showed a positive effect of Religious A-I discrepancy on RSWB ( $\beta$ $=.215, p<.001)$. The adequately fitting A-O model in Figure $6(\mathrm{df}=129, p<.001$, $\mathrm{C} / \mathrm{min}=2.224 ; \mathrm{CFI}=.971 ; \mathrm{RMSEA}=.055(90 \% \mathrm{CI} .046-.063)$, pclose $=.176)$ showed Religious A-O discrepancies positively effecting $\operatorname{RSWB}(\beta=.144, p=.023)$ and negatively effecting ESWB $(\beta=-.196, p<.001)$. Cultural self-discrepancies did not significantly impact spiritual well-being in either model.

The last analyses explored the possibility that Membership Self-Esteem or Importance to Identity may moderate the relationship between Jewish self-discrepancies and anxiety, depression, and/or spiritual well-being (hypotheses 5 and 6). After entering interaction terms into the appropriate models, all but one interaction term resulted in a non-significant moderating effect on the dependent variables (refer to Tables $4 \& 5$ ). The one exception shows membership self-esteem strengthening the negative relationship between Religious A-I discrepancies and ESWB (Interaction $\beta=-.110, p=.026$ ); individuals reporting a stronger sense of belonging to their Jewish identity and community experience a larger drop in existential well-being in the presence of larger 
Religious A-I self-discrepancies (see Figure 7). While the moderating relationship is statistically significant, it should be noted that the direct effect of Religious A-I discrepancies on ESWB was found to be non-significant. 


\section{DISCUSSION}

Contemporary American Jews are individually defining their own Jewishness based on both religious and cultural foundations (Cohen \& Eisen, 2000), yet there is limited empirical research on the experience of Jewish identity and its impact on overall well-being. Building upon the foundation established by Rogers (1954) and Higgins (1986), the perception of not being a "good enough Jew" can be conceptualized as selfdiscrepancies in one's Jewish identity and may result in negative psychological and spiritual consequences. The current study sought to identify Actual-Ideal and ActualOught self-discrepancies within one's Jewish identity, explore the differing impact of religious and cultural sources of the discrepancies, and determine if such selfdiscrepancies predict lower mental and spiritual well-being.

It was predicted that the overall sample of Jewish individuals would identify the presence of Jewish self-discrepancies. Jewish self-discrepancies illustrate the presence of the "yardstick" of Judaism that is either personally desired (Ideal) or environmentally expected (Ought), influencing the internalized perception of not being a "good enough Jew" (Horowitz, 1999). Participants in this study identified significant A-I and A-O discrepancies within the medium to large effect size ranges, demonstrating the strong tendency for Jewish individuals in this sample to recognize gaps between their current Jewish identity and either their desired or expected identity.

There were mixed results concerning the expected decreasing size of Jewish selfdiscrepancies as the individual's denominational affiliation becomes more traditional. 
Reform and Conservative Jews reported similar A-I and A-O discrepancies while showing larger discrepancies than the Orthodox sample. Orthodox Jews reported lower self-discrepancies likely due to their more stringent religious and cultural practices built into their perceived denominational identity and everyday routine (as evidenced by higher Actual AJIS scores), whereas Reform and Conservative Jews were aware of the gaps between their current identity and the internalized yardstick. Interestingly, the "Just Jewish" sample (i.e., Secular, Humanist, Atheist, and Agnostic) reported small discrepancies that mirrored the Orthodox sample. Individuals within the Just Jewish category report an actual identity more closely matching their desired or expected level, suggesting that the traditional yardstick is not as salient when exploring one's Jewish identity for non-denominational Jews.

Religious discrepancies were significantly larger than Cultural discrepancies across samples and denominations. Religious discrepancies accounted for approximately $70 \%$ of both the A-I and A-O discrepancies, showing mean discrepancy scores twice the size of Cultural discrepancies. Jews were more likely to report current adherence to Judaic cultural values, attitudes, behavioral lifestyles, and cultural traditions while being less likely to observe religious practices and beliefs. The higher scores on the Cultural Identity scale as compared to Religious Identity scales is consistent with Friedlander et al.'s (2010) initial exploration of the AJIS and also provides the foundation to identify larger religious discrepancies when accounting for the Ideal and Ought perspectives. Judaism's distinction as a "descent" religion emphasizes heredity and cultural-ethnic practices over religiously dogmatic beliefs (Cohen \& Hill, 2007; Morris, 1997), as reflected in the smaller cultural discrepancies. 
After controlling for perfectionism, Jewish self-discrepancies were expected to negatively relate to mental well-being, a hypothesis that garnered mixed results. Perfectionism was a significant predictor of higher anxiety and depression, warranting its inclusion within the path models. Religious A-I discrepancies showed a small effect on both anxiety and depression while Cultural A-I discrepancies did not have any additional significant effect on mental well-being. Jewish individuals reporting that their Actual Jewish Identity did not include religious practices and beliefs to the extent they personally desired reported more anxiety and depression. The perception that one is failing to maintain the attributes and standards of the Ideal self often leads to depressionrelated emotions due to one's failure to obtain desired positive outcomes (Higgins et al., 1986a; McDaniel \& Grice, 2008). Within this context, Jews with larger Religious A-I discrepancies are not receiving the positive consequences that are perceived to accompany their Ideal Religious Identity, such as weekly reminders of one's belongingness to the Judaic community during Sabbath rituals and additional holidays.

Analysis of the A-O discrepancy model showed Cultural A-O discrepancies negatively impacting anxiety and depression while Religious A-O discrepancies did not demonstrate an additional effect. The Actual-Ought discrepancy is driven by the perceived presence of negative outcomes by not fulfilling the sense of duty, obligation, or responsibility held by the standards of the Ought self (Higgins et al., 1986a); the Ought self is activated when one does not "measure up" to the traditional yardstick emphasized by one's idiosyncratic experience of Judaism. Therefore, this significant effect implies that Jews recognizing that they are not as culturally active as they ought to be to meet the requirements of a "good enough Jew" experience more anxiety and depression. Particular 
cultural areas that participants identified as contributing to larger Cultural A-O discrepancies include perceived importance of marrying within the religion, contributing and participating in Jewish organizations, and feeling a strong connection to Israel. Individuals discrepant in these attributes and other cultural areas may feel a lack of connection with one's cultural-ethnic identity, reduced social support, or fewer internalized buffers for stress and discrimination.

Jewish self-discrepancies were hypothesized to have a negative impact on spiritual well-being, a concept separated into its existential and religious components. The only pathway that supported the hypotheses highlighted a small negative effect of Religious A-O discrepancies on existential spiritual well-being. Existential spiritual wellbeing seeks to measure satisfaction with life and the quality of one's relationship to self, community, and surroundings; existential spiritual well-being was strongly negatively correlated with depression. Individuals with higher Religious A-O discrepancies reported lower satisfaction with life and higher distress concerning one's perceived future (e.g., "I feel unsettled about my future"), possibly due to perceived negative consequences from falling short on their religious expectations and losing out on positive benefits from their Jewish community.

Unexpectedly, Religious A-I and A-O discrepancies had a small positive effect on religious spiritual well-being, such that larger religious discrepancies predicted a stronger and more satisfying relationship with God or a higher power. The lack of a negative relationship between Jewish discrepancies and RSWB is likely due to the priority of cultural identity as well as a more distal relationship between Jewish identity and God. The items on the Religious Identity scale of the AJIS refer to observance of religious 
laws, principles, and rituals originally designed to increase one's relationship with God and/or observe a commandment. However, while every item on the RSWB scale includes "God," direct mention or connection to God is absent in the AJIS. There are multiple possible explanations as to why Jewish discrepancies, particularly those defined more by cultural influences, did not predict lower connection to the divine: Jews place more importance on practice and ritual over religious belief (Cohen et al., 2003), endorse a lower expectation that religious behaviors represent or enact internal beliefs, focus less on connection to God to shape important life and religious experiences (Cohen \& Hill, 2007), show less predictive impact of religious beliefs on mental health as compared to Christians (Rosmarin et al., 2009b), and do not show a predictive relationship between coping through God and life satisfaction (Cohen, 2002).

In contrast to Christianity, Gilman (1990) stated "Most Jews, even the most authentic among us, have never given much thought to clarifying just what we believe about God, nor do we feel that our religiosity is any the worse for it" (preface, p. xx). Within individual prayer, Jews are less likely to use colloquial or meditative prayer types directly involving God (Winkeljohn Black, Pössel, Jeppsen, Tariq, \& Rosmarin, 2014) or to require forgiveness from God to achieve self-forgiveness as compared to Christian samples (Exline, 2008; Goldstein \& Leach, 2010). Therefore, the lack of a negative impact of self-discrepancies on religious well-being illustrates that one's idiosyncratically experienced connection to God is relatively separate from one's involvement in their Jewish cultural-ethnic identity and shielded from any detrimental impact of Jewish discrepancies. 
Neither the current model nor the above exploration accounts for a mediating variable that does explain the positive relationship between Religious self-discrepancies and religious spiritual well-being. The measurement of Religious discrepancies requires the individual to be aware of their ideal desires, expected obligations, and internalized yardsticks representing their religious identity and then recognize how their current religious identity falls short of this measurement. The ability for an individual to identify their own religious discrepancies may influence one's striving and desire for a closer relationship with God achieved through observing God's commandments and participating in one's Jewish community. In turn, higher religious striving may increase everyday awareness of opportunities to connect to God (through Judaic and/or general methods), resulting in higher spiritual well-being. Another possibility is that those individuals with religious discrepancies feel disconnected from their Jewish community and imbedded social supports and therefore seek intrapersonal coping behaviors that maintain or increase their personal relationship to God. While personal prayer and asking forgiveness from God are not as frequently used for coping among Jewish as compared to Christian samples (Krause \& Ellison, 2003; Winkeljohn Black et al., 2014), such behaviors may improve one's connection to God even during the presence of a religious discrepancy.

The final research questions hypothesized that the relationship between Jewish self-discrepancies and well-being may be moderated by either Membership Self-Esteem or Judaism's Importance to Identity. However, across all analyses, the only significant interaction showed that Membership Self-Esteem strengthened the negative relationship between Religious A-I discrepancies and existential spiritual well-being. Jews that 
perceived themselves to be strong members of their Jewish community experienced lower satisfaction with life and more concern about their future when also identifying their own failure to participate in their religious-cultural community to the extent of their personal goals. While the interaction effect was significant, it should be noted that the direct effect of Religious A-I discrepancies on existential spiritual well-being was not found to be significant. Membership Self-Esteem, or one's positive sense of self as a member of their Jewish cultural-ethnic community, was positively correlated with both religious and spiritual well-being and negatively correlated with anxiety and depression, suggesting that one's perceived connection to their ethnic identity is a protective factor. The relationship between self-discrepancies and well-being did not change due to the importance and salience of one's Jewish identity. Such a result may be a reflection of the increased secularization of American Jewish identity and a reflection of a relatively small traditional Jewish sample where Jewish identity is expected to be a defining feature of one's identity.

\section{Clinical Implications}

Within the discussion of developing affirmative therapy and improved psychological treatment for mental disorders among American Jews (Friedman, Friedlander, \& Blustein, 2005; Schlosser, 2009), one pervasive point of emphasis is that there is no one face of American Jewry and that within-group variability makes the Jewish population difficult but necessary to study. The current line of research provides evidence that an idiosyncratic exploration of both current Jewish identity and subsequent discrepancies can provide more accurate insight into mental and spiritual well-being beyond denomination or frequency of synagogue attendance. When exploring Jewish 
identity in therapy, Schlosser (2006) called for the exploration of both adherence to Judaic rituals and involvement in their Jewish community while also recognizing that assumptions made purely from reported denominational affiliation, the standard practice of exploring Jewish identity to date (Hartman \& Kaufman, 2006), may be uninformative.

Therefore, affirmative therapy for Jewish individuals would include an exploration of Jewish identity as an intersection of cultural and religious identities. As supported both by the significantly higher cultural identity scores as compared to religious scores and the relatively large sample of "Just Jewish" participants consistent with demographic information, a large number of American Jews identify as Jewish culturally but not religiously (Klaff, 2006; Kugelmass, 2009). However, regardless of religious commitment, discrepancies in Jewish identity that more predominately measured culturally-experienced practices, rituals, and values negatively impacted wellbeing. Ideal discrepancies are akin to stating that "I wish I was participating in more Jewish activities" while Ought discrepancies imply that "I should be more involved within my Jewish community." The negative impact of these discrepancies due to lower participation in one's Jewish identity appears to be parallel to previous research demonstrating the protective strength of Jewish ethnic identity against discrimination, stress, and mental illness (Dubow, 2000; Friedlander et al., 2010). Collective self-esteem is consistently related to positive well-being and satisfaction with life (Kakhnovets \& Wolf, 2011), and as the majority of the religious and cultural items explored within this study are completed within a community environment, discrepancies would translate to a reduction in social support and lack of positive consequences that would stem from one's Jewish community. 
The clinical importance of discrepancies in Jewish identity may be shaped by the spirit of motivational interviewing (Miller \& Rollnick, 1991). The identification of discrepancies provides the opportunity to explore the negative impact of maintaining the discrepancies, assess motivation to change one's behaviors, and highlight individualized change talk with the overall goal of moving one's Actual identity closer to their Ideal or Ought goals. Utilization of the AJIS may signal whether the desired changes involve increases in religious observances, perceived connection to God, involvement in Judaic synagogues or organizations, or adherence to Jewish values that would increase one's connection to their Jewish identity.

As demonstrated in this study, Jews reporting discrepancies may have a higher risk of mood disturbances partially attributed to avoidance of cultural activities, disconnection from one's Jewish community, feelings of rejection, and overall lack of social support. Some Jewish clients may identify a desire to increase their observance of God's commandments, whether it be with the intent of reducing Ought-related anxiety, improve perceived connection to God, or as a way to strengthen social affiliation. Other Jewish clients may report that a belief in God is not inherent in their Jewish identity and would benefit from therapy sensitive to this belief structure; in fact, the most common participant comment upon completion of the survey addressed the participant's assertion that a connection between Jewish identity and belief in God should not be assumed. However, as shown with the Religious self-discrepancies' positive relationship with religious well-being and negative influence on existential well-being, an individualized therapeutic exploration into the role one's beliefs has on their cultural participation and 
overall well-being could be beneficial in facilitating the client's insight into their overall Jewish identity.

\section{Limitations and Future Directions}

The most salient limitation to the current study is the unique method of measuring Jewish self-discrepancies through the repeated administration of the American Jewish Identity Scale (Friedlander et al., 2010). The AJIS was not designed to be completed from either the Ideal or Ought perspectives, and as this is the first time religious discrepancies were measured in this fashion, it is unknown if the identification of discrepancies was exaggerated or weakened. Established measures of personal discrepancies (e.g., Carver, Lawrence \& Scheier, 1999; Higgins et al., 1986a; Watson, 2004) have reported limitations that include difficulties differentiating between Ideal and Ought selves (Watson et al., 2010) and low prevalence of measurable discrepancies (Boldero \& Francis, 2010). The former limitation was addressed through random assignment to either the Ideal or Ought condition while the medium to large effect sizes for Jewish discrepancies that were found within this sample do not support the latter concern. However, as within-subject differential impacts of A-I and A-O discrepancies on well-being were not explored, future research may benefit from adequately exploring both internalized desires and obligations in regards to their Jewish identity. One possible method to address self-discrepancy research limitations may be the use of a combined idiographic-nomothetic instrument where participants choose personally salient practices and beliefs and then rank their participation from the various discrepancy perspectives; such a method for identifying overall self-discrepancies showed better differentiation 
between Ideal and Ought discrepancies and more clearly predicted dependent variables (Hardin \& Lakin, 2009).

Another limitation present in this study is the possible presence of unmeasured constructs that impact the identification and presentation of religious and cultural identities as well as mental and spiritual well-being. The increased secularization of Judaism across nearly all denominations may indicate that Jewish self-discrepancies are more difficult to identify and/or more easily accepted within one's community (Horowitz, 1999). Perfectionism as a control variable and the moderating variables of Membership Self-Esteem and Importance to Identity were chosen to help parse out any interactions due to broader constructs of personal or collective identity. However, the inconsistent results as well as the unexpected relationship between discrepancies and religious spiritual well-being further suggest that this study does not include pertinent variables that would explain a significant amount of variance in mental and spiritual well-being (e.g., social support through Jewish community or religious striving/coping). Future research may also benefit from the inclusion of additional scales sensitively exploring the role of God within Jewish religious identity, better distinguishing between the religious and cultural constructs of Jewish self-identification (e.g, religious coping or attachment to God).

Additional limitations concern the generalizability of these results to reflect the international Jewish population. As suggested by the title of the scale, the items of the AJIS were designed and selected specifically to represent the Jewish experience in America in contrast to Israeli individuals; for example, some items included on the AJIS have specifically Jewish connotations in America while being necessary in Israel, such as 
reading Hebrew or knowing the date on the Israeli calendar. As highlighted by Friedlander et al., (2010), the reliability, validity, and application of the AJIS for Jews living outside of North America is a question for future research to explore.

Characteristics of this study's sample also limits the generalizability of the results among American Jews. Jewish individuals were recruited predominately through snowball sampling and listservs for Jewish congregations and organizations. While this strategy resulted in a large sample size, it may be assumed that the majority of participants considered their Jewish identity to be personally important enough to show interest in completing the survey, a characteristic that may not be truly representative of the overall American Jewish population. The nature of the questionnaire, even while being completed anonymously, may introduce self-report bias through over-reporting Judaic participation and under-reporting distress or perfectionism, therefore dampening the impact of self-discrepancies on well-being. The online survey-based procedure and recruitment strategy also limited this sample to individuals with access and comfort to electronic amenities. Additionally, the current sample is overwhelmingly White, female, and upper-middle class. While these demographics are consistent with recent National Jewish Population surveys (2001), the results of this study are not able to represent all Jewish experiences. Further research is needed to clarify the development, influences, and consequences of Jewish and additional identity discrepancies across a more demographic and denominationally diverse sample, particularly within Orthodox communities where it is frequently more difficult to obtain large samples.

A highly desirable path for future research would be to explore the presence and impact of self-discrepancies for a wider range of religious, cultural, and ethnic identities 
with the goal of informing culturally affirming research and practice. A majority of instruments utilized today in religious studies abide by the traditional "yardstick" method only, determining the level of fit the individual participant demonstrates with a requirement of that specific identity (e.g., frequency of Church attendance, beliefs about God, or single-item question concerning affiliation). Pargament and Krumrei (2009) warn that many existing measures for spirituality are inappropriate because they are "functionally disconnected" from the lived experience, only providing superficial information about basic practices and beliefs and are not sensitive to non-Christian clients. Application of a similar procedure using appropriate scales sensitive to the sample's characteristics could help inform clinician's awareness, knowledge and skills to more effectively and competently work with a religiously and culturally diverse clientele. This study sought to elicit more information concerning the experience of American Jewry, but further studies can expand the scope of this research to understand religious and cultural discrepancies from idiosyncratic and multiculturally sensitive perspectives.

\section{Conclusion}

Contributing to the need for further exploration of Judaism in multicultural empirical research (Schlosser, 2006), this study asked a large Jewish sample to identify self-discrepancies in their Jewish identity and determine if the perception of not being a "good enough Jew" impacted mental or spiritual well-being. The Jewish participants reported discrepancies between their current Jewish identity, their personally desirable level of Judaic participation, and their internalized expectations as learned from their Jewish community and collective sense of identity. The Actual-Ideal and Actual-Ought discrepancies were found to predict anxiety, depression, and lower existential well-being. 
Characteristics of the discrepancies and the instruments utilized within this study support the importance of Judaism as a cultural identity emphasizing behaviors, rituals, and values practiced within one's identified Jewish community, suggesting that Jewish discrepancies reduce the positive consequences of community participation and increase vulnerability to distress. The positive relationship between religious self-discrepancies and religious spiritual well-being further supports the suggestion that the role of God and of personally-held beliefs is less central to Jewish identity as compared to other prominent religions. Clinical application for increasing the understanding and exploration of Judaism as an intersection of cultural, religious, and ethnic identities is discussed. 


\section{REFERENCES}

Altman, A. N. (2010). An examination of mediating and moderating variables in the relationship between Jewish identity, perceived discrimination, and well-being. Doctoral dissertation: Lehigh University.

Altman, A. N., Inman, A. G., Fine, S. G., Ritter, H. A., \& Howard, E. E. (2010). An exploration of Jewish ethnic identity. Journal of Counseling and Development, 88, 163-173. http://dx.doi.org/10.1002/j.1556-6678.2010.tb00005.x

Ano, G.G., \& Vasconcelles, E. B. (2005). Religious coping and psychological adjustment to stress: A meta-analysis. Journal of Clinical Psychology, 61, 461-480. http://dx.doi.org/10.1002/jclp.20049

Antony, M.M., Purdon, C. L., Huta, V., \& Swinson, R. P. (1998). Dimensions of perfectionism across the anxiety disorders. Behaviour Research and Therapy, 36, 1143-1154. http://dx.doi.org/10.1016/S0005-7967(98)00083-7

Barrett-Lennard, G. T. (1962). Dimensions of therapist response as causal factors in therapeutic change. Psychological Monographs, 76(43, Whole No. 562).

Bartsch, D. (2007). Prevalence of body dysmorphic disorder symptoms and associated clinical features among Australian university students. Clinical Psychologist, 11, 16-23. http://dx.doi.org/10.1080/13284200601178532

Bizman, A., \& Yinon, Y. (2004). Social self-discrepancies from own and other standpoints and collective self-esteem. The Journal of Social Psychology, 144, 101-113. http://dx.doi.org/10.3200/SOCP.144.2.101-114 
Bjelland, I., Dahl, A.A., Haug, T.T., \& Neckelmann, D. (2002). The validity of the Hospital Anxiety and Depression Scale: An updated literature review. Journal of Psychosomatic Research, 52, 69-77.

Boldero, J., \& Francis, J. (2000). The relation between self-discrepancies and emotion: The moderating roles of self-guide importance, location relevance, and social selfdomain centrality. Journal of Personality and Social Psychology, 78, 38 - 52. http://dx.doi.org/10.1037/0022-3514.78.1.38

Bonelli, R.M. \& Koenig, H.G. (2013). Mental disorders, religion and spirituality 19902010: A systematic evidence-based review. Journal of Religion and Health, 52, 657-673.

Brown, R. M. (1995). Introduction. In E. Wiesel, The trial of God (pp. vii-xix). New York: Schocken.

Carver, C. S., Lawrence, J. W., \& Scheier, M. F. (1999). Self-discrepancies and affect: Incorporating the role of feared selves. Personality and Social Psychology Bulletin, 25, 783-792. http://dx.doi.org/10.1177/0146167299025007002

Cohen, A. B. (2002). The importance of spirituality in well-being for Jews and Christians. Journal of Happiness Studies, 3, 287-310. http://dx.doi.org/10.1023/A:1020656823365

Cohen, A.B., \& Eisen, A.M. (2000). The Jew within. Bloomington: Indiana University Press.

Cohen, A.B. \& Hill, P.C. (2007). Religion as culture: Religious individualism and collectivism among American Catholics, Jews, and Protestants. Journal of Personality, 75, 709-742. 
Cohen, A. B., Siegel, J. I., \& Rozin, P. (2003). Faith versus practice: Different bases for religiosity judgments by Jews and Protestants. European Journal of Social Psychology, 33, 287-295. http://dx.doi.org/10.1002/ejsp.148

Charme, S., Horowitz, B., Hyman, T., \& Kress, J.S. (2008). Jewish identities in action: An exploration of models, metaphors, and methods. Journal of Jewish Education, 74, 115-143. http://dx.doi.org/10.1080/15244110802126640

Dawes, J. (2008). Do data characteristics change according to the number of scale points used? An experiment using 5-point, 7-point and 10-point scales. International Journal of Market Research, 50, 61-77.

Dubow, E.F., Pargament, K.I., Boxer, P., \& Tarakeshwar, N. (2000). Initial investigation of Jewish early adolescents' ethnic identity, stress, and coping. Journal of Early Adolescence, 20, 418-441.

Enns, M. W., \& Cox, B. J. (2002). Nature and assessment of perfectionism. In G. L. Flett \& P.L. Hewitt (Eds.), Perfectionism: Theory, research and treatment (pp. 33-62). Washington, DC: American Psychological Association. http://dx.doi.org/10.1037/10458-002

Exline, J.J. (2008). Beliefs about God and forgiveness in a Baptist Church sample. Journal of Psychology and Christianity, 27(2), 131-139.

Exline, J. J., Yali, A. M., \& Sanderson, W. C. (2000). Guilt, discord and alienation: The role of religious strain in depression and suicidality. Journal of Clinical Psychology, 56, 1481-1496. http://dx.doi.org/10.1002/10974679(200012)56:12<1481::AID-1>3.0.CO;2-A 
Flett, G. L., \& Hewitt, P. L. (2002). Perfectionism and maladjustment: An overview of theoretical, definitional, and treatment issues. In G. L. Flett \& P. L. Hewitt (Eds.), Perfectionism: Theory, research, and treatment (pp. 5-31). Washington, DC: American Psychological Association. http://dx.doi.org/10.1037/10458-001

Flett, G. L., Hewitt, P. L., Blankstein, K. R., \& O’Brien, S. (1991). Perfectionism and learned resourcefulness in depression and self-esteem. Personality and Individual Differences, 12, 61- 68. http://dx.doi.org/10.1016/0191-8869(91)90132-U

Friedlander, M.L., Friedman, M.L., Miller, M.J., Ellis, M.V., Friedlander, L.K., \& Mikhaylov, V.D. (2010). Introducing a brief measure of cultural and religious identification in American Jewish identity. Journal of Counseling Psychology, 57, 345-360. http://dx.doi.org/10.1037/a0019577

Friedman, M.L., Friedlander, M.L., \& Blustein, D.L. (2005). Toward an understanding of Jewish identity: A phenomenological study. Journal of Counseling Psychology, $52,77-83$.

Genia, V. (2001). Evaluation of the Spiritual Well-Being Scale in a sample of college students. International Journal for the Psychology of Religion, 11, 25-33.

Gilman, N. (1990). Sacred fragments: Recovering theology for the modern Jew. Philadelphia: Jewish Publication Society.

Goldstein, J. \& Leach, M.M. (2010, August). Self-forgiveness and self-condemnation among Christians and Jews. Poster presentation at the 118th Annual Convention of the American Psychological Association, San Diego, CA.

Goodman, J. M. (2002). Psychological well-being in the Jewish community: The impact of social identity and spirituality. Doctoral dissertation, Kent State University. 
Gramzow, R. H., Sedikides, C., Panter, A. T., \& Insko, C. A. (2000). Aspects of selfregulation and self-structure as predictors of perceived emotional distress. Personality and Social Psychology Bulletin, 26, 188-205. http://dx.doi.org/10.1177/0146167200264006

Hair, J., Black, W., Babin, B., \& Anderson, R. (2010). Multivariate data analysis (7 $7^{\text {th }}$ ed,): Prentice Hall, Inc: Saddle River, NJ.

Hankin, B.L., Roberts, J., \& Gotlib, I.H. (1997). Elevated self-standards and emotional distress during adolescence: Emotional specificity and gender differences. Cognitive Therapy and Research, 21, 663-679. http://dx.doi.org/10.1023/A:1021808308041

Hardin, E.E., \& Lakin, J.L. (2009). The Integrated Self-Discrepancy Index: A reliable and valid measure of self-discrepancies. Journal of Personality Assessment, 91, 245-253. http://dx.doi.org/10.1080/00223890902794291

Hart, D., Field, N.P., Garfinkle, J.R., \& Singer, J.L. (1997). Representations of self and other: A semantic space model. Journal of Personality, 65, 77 - 105. http://dx.doi.org/10.1111/j.1467-6494.1997.tb00530.x

Heimberg, R. G., Juster, H. R., Hope, D. A., \& Mattia, J. I. (1995). Cognitive behavioral group treatment: description, case presentation, and empirical support. In M. B. Stein (Ed.), Social phobia: Clinical and research perspectives (pp. 293-321). Washington, DC: American Psychiatric Press.

Hewitt, P.L., \& Flett, G.L. (1991). Perfectionism in the self and social contexts: Conceptualization, assessment, and association with psychopathology. Journal of 
Personality and Social Psychology, 60, 456-470. http://dx.doi.org/10.1037/00223514.60 .3 .456

Hewitt, P. L., Flett, G.L., \& Ediger, E. (1995). Perfectionism traits and perfectionistic self-presentation in eating disorder attitudes, characteristics, and symptoms. International Journal of Eating Disorders, 18, 317- 326.

http://dx.doi.org/10.1002/1098-108X(199512)18:4<317::AID-

EAT2260180404>3.0.CO;2-2

Higgins, E. T. (1987). Self-discrepancy: A theory relating self and affect. Psychological Review, 94, 319 - 340. http://dx.doi.org/10.1037/0033-295X.94.3.319

Higgins, E.T., Bond, R.N., Klein, R., \& Strauman, T. (1986a). Self-discrepancies and emotional vulnerability: How magnitude, accessibility, and type of discrepancy influence affect. Journal of Personality and Social Psychology, 51, 5-15. http://dx.doi.org/10.1037/0022-3514.51.1.5

Higgins, E.T., Strauman, T., \& Klein, R. (1986b). Standards and the process of selfevaluation: Multiple affects from multiple stages. In R.M. Sorrentino \& E.T. Higgins (Eds.), Handbook of motivation and cognition: Foundations of social behavior (pp. 22-63). New York: Guilford Press.

Horowitz, B. (1999). Indicators of Jewish identity: Developing a framework for understanding American Jewry. New York: Mandel Foundation.

Horowitz, B. (2002). Reframing the study of contemporary American Jewish identity. Contemporary Jewry, 23, 14-34. http://dx.doi.org/10.1007/BF02967927

James, W. (1890). The principles of psychology. New York: Henry Holt \& Company. http://dx.doi.org/10.1037/11059-000 
Kakhnovets, R., \& Wolf, L. (2011). An investigation of Jewish ethnic identity and Jewish affiliation for American Jews. North American Journal of Psychology, 13, 501518.

Klaff, V. (2006). Defining American Jewry from religious and ethnic perspectives: The transitions to greater heterogeneity. Sociology of Religion, 67, 415-438. http://dx.doi.org/10.1093/socrel/67.4.415

Koenig, H.G., McCullough, M.E., \& Larson, D.B. (2001). Handbook of Religion and Health. Oxford: Oxford University Press. http://dx.doi.org/10.1093/acprof:oso/9780195118667.001.0001

Krause, N., \& Ellison, C.G. (2003). Forgiveness by God, forgiveness of others, and psychological well-being in late life. Journal of Psychology and Theology, 42, 7794.

Langman, P. F. (1999). Jewish issues in multiculturalism. Northvale, NJ: Jason Aronson, Inc.

Large, M.D., \& Marcussen, K. (2000). Extending identity theory to predict differential forms and degrees of psychological distress. Social Psychology Quarterly, 63, 4959. http://dx.doi.org/10.2307/2695880

Lilliston, L., \& Klein, D.G. (1991). A self-discrepancy reduction model of religious coping. Journal of Clinical Psychology, 47, 854-860.

http://dx.doi.org/10.1002/1097-4679(199111)47:6<854::AIDJCLP2270470617>3.0.CO;2-H 
Luhtanen, R., \& Crocker, J. (1992). A Collective Self-Esteem Scale: Self-evaluation of one's social identity. Personality and Social Psychology Bulletin, 18, 302-318. http://dx.doi.org/10.1177/0146167292183006

McConnell, K. M., Pargament, K. I., Ellison, C. G., \& Flannelly, K. J. (2006). Examining the links between spiritual struggles and symptoms of psychopathology in a national sample. Journal of Clinical Psychology, 62, 1469-1484. http://dx.doi.org/10.1002/jclp.20325

McDaniel, B.L., \& Grice, J.W. (2008). Predicting psychological well-being from selfdiscrepancies: A comparison of idiographic and nomothetic measures. Self and Identity, 7, 243-261. http://dx.doi.org/10.1080/15298860701438364

Miller, W.R., \& Rollnick, S. (1991). Motivational interviewing: Preparing people for change. New York: Guilford Press.

Molnar, D.S., Reker, D.L., Culp, N.A., Sadava, S.W., \& DeCourville N.H. (2006). A mediated model of perfectionism, affect, and physical health. Journal of Research in Personality, 40, 482-500. http://dx.doi.org/10.1016/j.jrp.2005.04.002

Moretti, M. M., \& Higgins, E. T. (1990). Relating self-discrepancy to self-esteem: The contribution of discrepancy beyond actual-self ratings. Journal of Experimental Social Psychology, 26, 108-123. http://dx.doi.org/10.1016/0022-1031(90)90071S

National Jewish Population Survey. (2001). The Jewish population. Retrieved from http://www.ujc.org/content_display.html?ArticleID_60645. 
Ozgul, S., Heubeck, B., Ward, J., \& Wilkinson, R. (2003). Self-discrepancies:

Measurement and relation to various negative affective states. Australian Journal of Psychology, 55, 56-62. http://dx.doi.org/10.1080/00049530412331312884

Paloutzian, R.F., \& Ellison, C.W. (1982). Loneliness, spiritual well-being, and the quality of life. In L.A. Peplan \& D. Pearlman (Eds.), Loneliness: A sourcebook of current theory, research, and therapy. New York: Wiley.

Pargament, K. I. (1999). The psychology of religion and spirituality? Yes and no. International Journal for the Psychology of Religion 9, 3-14. http://dx.doi.org/10.1207/s15327582ijpr0901_2

Pargament, K.I., \& Krumrei, E.J. (2009). Clinical assessment of clients' spirituality. In J.D. Aten \& M.M. Leach (Eds.), Spirituality and the therapeutic process: A comprehensive resource from intake to termination (pp. 93-120). Washington DC: American Psychological Association.

Pargament, K. I., Murray-Swank, N. A., Magyar, G. M., \& Ano, G. G. (2005). Spiritual struggle: A phenomenon of interest to psychology and religion. In W. R. Miller \& H. D. Delaney (Eds.), Judeo-Christian perspectives on psychology: Human nature, motivation, and change (pp. 245-268). Washington, DC: American Psychological Association. http://dx.doi.org/10.1037/10859-013

Pargament, K. I., Tarakeshwar, N., Ellison, C. G., \& Wulff, K. M. (2001). Religious coping among the religious: The relationship between religious coping and wellbeing in a national sample of Presbyterian clergy, elders, and members. Journal for the Scientific Study of Religion, 40, 497-513. http://dx.doi.org/10.1111/00218294.00073 
Parker, J. (2004). The effects of self-monitoring and religious self-discrepancies on negative affect. Masters Thesis: Western Kentucky University.

Petrocelli, J.V., \& Smith, E.R. (2005). Who I am, who we are, and why: Links between emotions and causal attributions for self- and group discrepancies. Personality and Social Psychology Bulletin, 31, 1628-1642.

http://dx.doi.org/10.1177/0146167205277390

Phillips, A. G., \& Silvia, P. J. (2005). Self-awareness and the emotional consequences of self-discrepancies. Personality and Social Psychology Bulletin, 31, 703-713. http://dx.doi.org/10.1177/0146167204271559

Phinney, J. (1996). When we talk about American ethnic groups, what do we mean? American Psychologist, 51, 918-927. doi: 10.1037/0003-066X.51.9.918

Rogers, C. R. (1951). Client-centered therapy: Its current practice, applications and theory. Boston, MA: Houghton Mifflin.

Rogers, C. R., \& Dymond, R. F. (1954). Psychotherapy and personality change: Coordinated research studies in the client-centered approach. Chicago, IL: University of Chicago Press.

Rosmarin, D.H., Pargament, K.I., \& Flannelly, K.J. (2009a). Do spiritual struggles predict poorer physical/mental health among Jews? The International Journal for the Psychology of Religion, 19, 244-258.

http://dx.doi.org/10.1080/10508610903143503

Rosmarin, D.H., Pirutinsky, S., Pargament, K.I., \& Krumrei, E.J. (2009b). Are religious beliefs relevant to mental health among Jews? Psychology of Religion and Spirituality, 1, 180-190. http://dx.doi.org/10.1037/a0016728 
Saboonchi, F., \& Lundh, L.G. (2003). Perfectionism, anger, somatic health, and positive affect. Personality and Individual Differences, 35, 1585-1599. http://dx.doi.org/10.1016/S0191-8869(02)00382-3

Schlosser, L. Z. (2006). Affirmative psychotherapy for American Jews. Psychotherapy: Theory, Research, Practice, Training, 43, 424-435. http://dx.doi.org/10.1037/0033-3204.43.4.424

Scott, L., \& O’Hara, M. W. (1993). Self-discrepancies in clinically anxious and depressed university students. Journal of Abnormal Psychology, 102, 282-287. http://dx.doi.org/10.1037/0021-843X.102.2.282

Slater, W., Hall, T.W., \& Edwards, K.J. (2001). Measuring religion and spirituality: Where are we and where are we going? Journal of Psychology and Theology, 29, 4-21.

Stoeber, J., \& Childs, J.H. (2010). The assessment of self-oriented and socially prescribed perfectionism: Subscales make a difference. Journal of Personality Assessment, 92, 577-585. http://dx.doi.org/10.1080/00223891.2010.513306

Strauman, T. J., Kolden, G. G., Stromquist, V., Kwapil, L., Schneider, K., Heerey, E., \& Schneider, K. (2001). The effects of treatments for depression on perceived failure in self-regulation. Cognitive Therapy and Research, 25, 693-712. http://dx.doi.org/10.1023/A:1012915205800

Tajfel, H. (1981). Human groups and social categories: Studies in social psychology. Cambridge, England: Cambridge University Press.

Tangney, J.P., Niedenhal, P.M., Covert, M.V., \& Barlow, D.H. (1998). Are shame and guilt related to distinct self-discrepancies? A test of Higgins's (1987) hypotheses. 
Journal of Personality and Social Psychology, 75, 256-268.

http://dx.doi.org/10.1037/0022-3514.75.1.256

Watson, N. (2004). Self-Concept Questionnaire-Personal Constructs, Self-Concept Questionnaire-Conventional Constructs, Abstract Measures of Real-Ideal and Real-Ought Discrepancies. Retrieved from http://www.wm.edu/research/watson.

Watson, N., Bryan, B.C., \& Thrash, T.M. (2010). Self-discrepancy: Comparisons of the psychometric properties of three instruments. Psychological Assessment, 22, 878892. http://dx.doi.org/10.1037/a0020644

Winkeljohn Black, S., Pössel, P., Jeppsen, B. D., Tariq, A., \& Rosmarin, D. H. (2014, December 22). Poloma and Pendleton's (1989) Prayer Types Scale in Christian, Jewish, and Muslim Praying Adults: One Scale or a Family of Scales?. Psychology of Religion and Spirituality. Advance online publication. http://dx.doi.org/10.1037/rel0000018

Wyatt, R., \& Gilbert, P. (1998). Dimensions of perfectionism: A study exploring their relationship with perceived social rank and status. Personality and Individual Differences, 24, 71- 79. http://dx.doi.org/10.1016/S0191-8869(97)00146-3

Zigmund, A.S., \& Snaith, R.P. (1983). The hospital anxiety and depression scale. Acta Psychiatrica Scandinavica, 67, 361-370. 


\section{APPENDIX A: SURVEY INSTRUMENTS}

\section{American Jewish Identity Scale}

Please indicate the extent each of the following items represents your Jewish identity.

$1=$ not at all true of me, $2=$ rarely true of me, $3=$ a little true of me, $4=$ sometimes true of me, 5= fairly true of me, $6=$ almost always/very true of me, $7=$ always true of me

1. I observe the Sabbath.

2. I enjoy Jewish literature.

3. I deliberately seek out Jewish professionals (health care providers, realtors, etc.).

4. I read Jewish newspapers.

5. I am embarrassed, ashamed or angry when a Jew does something criminal.

6. I study Jewish religious texts (e.g., Torah, Talmud, Gemora).

7. I try to follow all Jewish commandments in my daily life.

8. I am proud to be Jewish.

9. I believe in the coming of the Messiah.

10. Being ethnically Jewish is more important to me than my nationality.

11. I show my Jewish identity to others by the way I dress.

12. It is important for me to date or marry a Jew.

13. I make contributions to Jewish causes.

14. I regularly keep my head covered for religious reasons.

15. A member of my household lights candles on the Sabbath.

16. I have a mezuzah in my home.

17. I know today's date on the Hebrew calendar.

18. I listen to Jewish secular music.

19. I feel connected to Judaism through my personal ancestors.

20. I celebrate all Jewish holidays.

21. My sense of being Jewish is constant no matter where I am.

22. "Tikkun Olam" (healing the world") is a Jewish value that is important to me.

23. I follow the dietary rules of Passover.

24. I read Hebrew.

25. I keep Kosher.

26. I dress in accordance with Jewish religious commandments.

27. I feel a strong connection to Israel.

28. I am active in a Jewish community center or organization.

29. I regularly go to a Mikvah

30. I fast on Yom Kippur.

31. I attend Jewish religious services at a temple, synagogue, or stiebel.

32. When in mourning, I observe all Jewish religious rituals.

33. I ritually wash my hands before eating bread. 


\section{Multidimensional Perfectionism Scale}

Listed below are a number of statements concerning your personal characteristics and traits. Read each item and decide whether you agree or disagree and to what extent.

1= Strongly Disagree, 2= Disagree, $3=$ Slightly Disagree, 4= Neutral, 5= Slightly Agree, 6= Agree, $7=$ Strongly Agree

Self-oriented perfectionism

1) When I am working on something, I cannot relax until it is perfect.

2) One of my goals is to be perfect in everything I do.

3) I never aim for perfection in my work.

4) I seldom feel the need to be perfect.

5) I strive to be as perfect as I can be.

6) It is very important that I am perfect in everything I attempt.

7) I strive to be the best in everything that I do.

8) I demand nothing less than perfection of myself.

9) It makes me uneasy to see an error in my work.

10) I am perfectionistic in setting my goals.

11) I must work to my full potential at all times.

12) I do not have to be the best whatever I am doing.

13) I do not have very high goals for myself.

14) I set very high standards for myself.

15) I must always be successful at school or work.

Socially prescribed perfectionism

1) I find it difficult to meet other's expectations of me.

2) Those around me readily accept that I can make mistakes too.

3) The better I do, the better I am expected to do.

4) Anything I do that is less than excellent will be seen as poor work by those around me.

5) The people around me expect me to succeed at everything I do.

6) Others will like me even if I don't excel at everything.

7) Success means that I must work even harder to please others.

8) Others think I am okay, even when I do not succeed.

9) I feel that people are too demanding of me.

10) Although they may not show it, other people get very upset with me when I slip up.

11) My family expects me to be perfect.

12) My parents rarely expect me to excel in all aspects of my life.

13) People expect nothing less than perfection from me.

14) People expect more from me than I am capable of.

15) People around me think I am competent even if I make a mistake. 


\section{Collective Self-Esteem Scale}

We are all members of different social groups or social categories. We would like you to consider your Jewish ethnicity in responding to the following statements. There are no right or wrong answers to any of these statements; we are interested in your honest reactions and opinions.

Please read each statement carefully, and respond by using the following scale from 1 to 7: 1= Strongly Disagree, 2= Disagree, 3= Slightly Disagree, 4= Neutral, 5= Slightly Agree, 6= Agree, $7=$ Strongly Agree

Membership Self-Esteem

1) I am a worthy member of my Jewish community.

2) I feel I don't have much to offer to my Jewish community.

3) I am a cooperative participant in the activities of my Jewish community.

4) I often feel I'm a useless member of my Jewish community. Importance to Identity

1) Overall, my Jewish identity has very little to do with how I feel about myself.

2) The Jewish group I belong to is an important reflection of who I am.

3) My Jewish identity is unimportant to my sense of what kind of a person I am.

4) In general, belong to my Jewish identity is an important part of my self-image.

\section{Spiritual Well-Being Scale}

For each of the following statements, choose the description that best indicates the extent of your agreement as it describes your personal experience.

1= Strongly Disagree, 2= Disagree, 3= Slightly Disagree, 4=Slightly Agree, 5= Agree, 6= Strongly Agree

1. I don't find much satisfaction in private prayer with God.

2. I don't know who I am, where I came from, or where I'm going.

3. I believe that God loves me and cares about me.

4. I feel that life is a positive experience.

5. I believe that God is impersonal and not interested in my daily situations.

6. I feel unsettled about my future.

7. I have a personally meaningful relationship with God.

8. I feel very fulfilled and satisfied with life.

9. I don't get much personal strength and support from my God

10. I feel a sense of well-being about the direction my life is headed in.

11. I believe that God is concerned about my problems.

12. I don't enjoy much about life.

13. I don't have a personally satisfying relationship with God.

14. I feel good about my future.

15. My relationship with God helps me not to feel lonely.

16. I feel that life is full of conflict and unhappiness.

17. I feel most fulfilled when I'm in close communion with God.

18. Life doesn't have much meaning.

19. My relation with God contributes to my sense of well-being.

20. I believe there is some real purpose for my life. 


\section{Depression Anxiety Stress Scale-21}

Please read each statement and circle a number $0,1,2$ or 3 which indicates the response that comes closest to how you have been feeling in the past week.

1) I feel tense of "wound up": 0) Most of the time; 1) A lot of the time; 2) From time to time, occasionally; 4) Not at al.

2) I still enjoy the things I used to enjoy: 0) Definitely as much; 2) Not quite so much; 3) Only a little; 4) Hardly at all.

3) I get a sort of frightful feeling as if something awful is about to happen: 0) Very definitely and quite badly; 1) Yes, but not too badly; 2) A little, but it doesn't worry me; 3) Not at all.

4) I can laugh and see the funny side of things: 0) As much as I always could; 1) Not quite so much now; 2) Definitely not so much now; 3) Not at all.

5) Worrying thoughts go through my mind: 0) A great deal of the time; 1) A lot of the time; 2) From time to time, but not too often; 3) Only occasionally.

6) I feel cheerful: 0) Not at all; 1) Not often; 2) Sometimes; 3) Most of the time.

7) I can sit at ease and feel relaxed: 0) Definitely; 1) Usually; 2) Not often; 3) Not at all.

8) I feel as if I am slowed down: 0) Nearly all the time; 1) Very often; 2) Sometimes; 3) Not at all.

9) I get a sort of frightened feeling like "butterflies" in the stomach: 0) Not at all; 1) Occasionally; 2) Quite often; 3) Very often.

10) I have lost interest in my appearance: 0 ) Definitely; 1) I don't take as much care as I should; 2) I may not take quite as much care; 3) I take just as much care as ever.

11) I feel restless as if I have to be on the move: 0) Very much indeed; 1) Quite a lot; 2) Not very much; 3) Not at all.

12) I look forward with enjoyment to things: 0 ) As much as I ever did; 1) Rather less than I used to; 2) Definitely less than I used to; 3) Hardly at all.

13) I get sudden feelings of panic: 0) Very often indeed; 1) Quite often; 2) Not very often; 3) Not at all.

14) I can enjoy a good book, radio or TV program: 0) Often; 1) Sometimes; 2) Not often; 3) Very seldom 
APPENDIX B: TABLES AND FIGURES

Table 1.

Intercorrelations of the Major Variables

\begin{tabular}{|c|c|c|c|c|c|c|c|c|c|}
\hline & $\overline{\text { AJIS_R }}$ & $\overline{\text { AJIS_C }}$ & ESWB & RSWB & Depression & Anxiety & MSE & IISE & Perfectionism \\
\hline AJIS_R & $\begin{array}{ll}--- \\
---\end{array}$ & & & & & & & & \\
\hline AJIS_C & $.629 * *$ & ---- & & & & & & & \\
\hline ESWB & $.078^{*}$ & $.171 * *$ & ---- & & & & & & \\
\hline RSWB & $.577 * *$ & $.365^{* *}$ & $.199 * *$ & ---- & & & & & \\
\hline Depression & -.026 & $-.073^{*}$ & $-.624 * *$ & -.057 & ---- & & & & \\
\hline Anxiety & $.085^{*}$ & -.002 & $-.475 * *$ & .055 & $.478 * *$ & ---- & & & \\
\hline MSE & $.355^{* *}$ & $.478 * *$ & $.386^{* *}$ & $.227 * *$ & $-.292 * *$ & $-.189 * *$ & ---- & & \\
\hline IISE & $.331 * *$ & $.463 * *$ & $.109 * *$ & $.216^{* *}$ & -.052 & .064 & $.463 * *$ & --- & \\
\hline Perfectionism & $.125^{* *}$ & .044 & $-.248 * *$ & $.091 * *$ & $.190 * *$ & $.378 * *$ & $-.153 * *$ & .022 & ---- \\
\hline$M$ & 3.29 & 4.89 & 5.46 & 3.82 & 1.45 & 2.02 & 5.74 & 5.41 & 3.93 \\
\hline$S D$ & 1.38 & .96 & .96 & 1.73 & .38 & .50 & 1.12 & 1.16 & .86 \\
\hline$\alpha$ & .94 & .83 & .87 & .96 & .76 & .81 & .81 & .68 & .78 \\
\hline
\end{tabular}

Notes: AJIS_R = Actual religious identity; AJIS_C = Actual cultural identity; AJIS on a 1-7 Likert scale; ESWB =

Existential spiritual well-being; RSWB = Religious spiritual well-being. MSE = Membership self-esteem; IISE = Importance to Identity self-esteem

$* p<.05 . * * p<.01$. 
Table 2

Actual, Ideal, and Ought Jewish Identity Means and Standard Deviations

\begin{tabular}{lclcc}
\hline & $\begin{array}{c}\text { Sample } \\
\text { Size }\end{array}$ & $\begin{array}{c}\text { Total Mean } \\
(\mathrm{SD})\end{array}$ & $\begin{array}{c}\text { Religious Mean } \\
(\mathrm{SD})\end{array}$ & $\begin{array}{c}\text { Cultural Mean } \\
(\mathrm{SD})\end{array}$ \\
\hline Actual Jewish Identity & 829 & $4.01(1.07)$ & $3.29(1.36)$ & $4.87(.95)$ \\
Reform & 304 & $3.87(.79)$ & $3.07(.90)$ & $4.84(.89)$ \\
Conservative & 213 & $4.49(.80)$ & $3.91(1.02)$ & $5.18(.74)$ \\
Orthodox & 68 & $5.78(.77)$ & $5.85(.97)$ & $5.69(.76)$ \\
Just Jewish & 197 & $3.09(.75)$ & $2.07(.75)$ & $4.32(.99)$ \\
Ideal Jewish Identity & 419 & $4.66(1.23)$ & $4.14(1.60)$ & $5.28(1.01)$ \\
Reform & 159 & $4.78(.94)$ & $4.23(1.17)$ & $5.43(.92)$ \\
Conservative & 100 & $5.20(.90)$ & $4.88(1.18)$ & $5.58(.79)$ \\
Orthodox & 39 & $6.13(.79)$ & $6.27(.93)$ & $5.96(.80)$ \\
Just Jewish & 101 & $3.42(1.02)$ & $2.50(1.21)$ & $4.55(1.04)$ \\
Ought Jewish Identity & 410 & $4.70(1.29)$ & $4.23(1.70)$ & $5.27(1.02)$ \\
Reform & 145 & $4.64(1.06)$ & $4.09(1.35)$ & $5.30(.88)$ \\
Conservative & 113 & $5.34(.85)$ & $5.12(1.15)$ & $5.60(.73)$ \\
Orthodox & 29 & $6.35(.36)$ & $6.58(.47)$ & $6.07(.51)$ \\
Just Jewish & 96 & $3.46(1.17)$ & $2.57(1.40$ & $4.54(1.21)$ \\
\hline
\end{tabular}


Table 3

Actual-Ideal and Actual-Ought Discrepancies Means, SDs, and Effect Sizes

\begin{tabular}{lccc|ccc}
\hline & $\begin{array}{c}\text { Religious } \\
\text { A-I }\end{array}$ & $\begin{array}{c}\text { Cultural } \\
\text { A-I }\end{array}$ & $\begin{array}{c}\text { Total A-I } \\
\text { Effect } \\
\text { Size }(d)\end{array}$ & $\begin{array}{c}\text { Religious } \\
\text { A-O }\end{array}$ & $\begin{array}{c}\text { Cultural } \\
\text { A-O }\end{array}$ & $\begin{array}{c}\text { Total A-O } \\
\text { Effect } \\
\text { Size }(d)\end{array}$ \\
\hline Total & $.84(.91)$ & $.45(.59)$ & .58 & $.95(1.07)$ & $.35(.74)$ & .58 \\
Reform & $1.12(.96)$ & $.58(.62)$ & 1.03 & $1.07(.99)$ & $.48(.72)$ & .86 \\
Conservative & $1.00(.83)$ & $.45(.52)$ & .88 & $1.15(1.04)$ & $.36(.65)$ & .96 \\
Orthodox & $.42(.82)$ & $.30(.60)$ & .49 & $.68(.88)$ & $.30(.78)$ & .77 \\
Just Jewish & $.43(.78)$ & $.31(.58)$ & .42 & $.52(1.14)$ & $.14(.86)$ & .36 \\
\hline
\end{tabular}


Table 4

Interaction Effects with Moderating Variables on Mental Well-Being

\begin{tabular}{lccc}
\hline \multicolumn{1}{c}{ Interaction Variable } & $\begin{array}{c}\text { Dependent } \\
\text { Variable }\end{array}$ & $\begin{array}{c}\text { Unstandardized } \\
\text { Regression Weight }\end{array}$ & $\begin{array}{c}\text { Significance } \\
\text { (p-value) }\end{array}$ \\
\hline Ideal Religious SD x MSE & Anxiety & .034 & .567 \\
Ideal Religious SD x MSE & Depression & .059 & .280 \\
Ideal Cultural SD x MSE & Anxiety & .003 & .909 \\
Ideal Cultural SD x MSE & Depression & -.026 & .615 \\
\hline Ideal Religious SD x IISE & Anxiety & .042 & .179 \\
Ideal Religious SD x IISE & Depression & .017 & .114 \\
Ideal Cultural SD x IISE & Anxiety & -.010 & .727 \\
Ideal Cultural SD x IISE & Depression & -.016 & .400 \\
\hline Ought Religious SD x MSE & Anxiety & .024 & .419 \\
Ought Religious SD x MSE & Depression & .049 & .102 \\
Ought Cultural SD x MSE & Anxiety & -.006 & .840 \\
Ought Cultural SD x MSE & Depression & -.051 & .072 \\
\hline Ought Religious SD x IISE & Anxiety & .006 & .871 \\
Ought Religious SD x IISE & Depression & .002 & .964 \\
Ought Cultural SD x IISE & Anxiety & .016 & .649 \\
Ought Cultural SD x IISE & Depression & $<.001$ & .997 \\
\hline
\end{tabular}


Table 5

Interaction Effects with Moderating Variables on Spiritual Well-Being

\begin{tabular}{llcc}
\hline \multicolumn{1}{c}{ Interaction Variable } & $\begin{array}{c}\text { Dependent } \\
\text { Variable }\end{array}$ & $\begin{array}{c}\text { Unstandardized } \\
\text { Regression Weight }\end{array}$ & $\begin{array}{c}\text { Significance } \\
\text { (p-value) }\end{array}$ \\
\hline Ideal Religious SD x MSE & ESWB & -.136 & $.026^{*}$ \\
Ideal Religious SD x MSE & RSWB & -.171 & .052 \\
Ideal Cultural SD x MSE & ESWB & .132 & .067 \\
Ideal Cultural SD x MSE & RSWB & .127 & .226 \\
\hline Ideal Religious SD x IISE & ESWB & -.133 & .065 \\
Ideal Religious SD x IISE & RSWB & -.119 & .230 \\
Ideal Cultural SD x IISE & ESWB & .072 & .299 \\
Ideal Cultural SD x IISE & RSWB & .088 & .348 \\
\hline Ought Religious SD x MSE & ESWB & -.106 & .097 \\
Ought Religious SD x MSE & RSWB & .007 & .949 \\
Ought Cultural SD x MSE & ESWB & .070 & .248 \\
Ought Cultural SD x MSE & RSWB & .007 & .943 \\
\hline Ought Religious SD x IISE & ESWB & -.024 & .786 \\
Ought Religious SD x IISE & RSWB & -.033 & .803 \\
Ought Cultural SD x IISE & ESWB & -.022 & .788 \\
Ought Cultural SD x IISE & RSWB & .097 & .440 \\
\hline
\end{tabular}


Figure 1.

Model of Jewish Self-Discrepancies on Mental Well-Being.

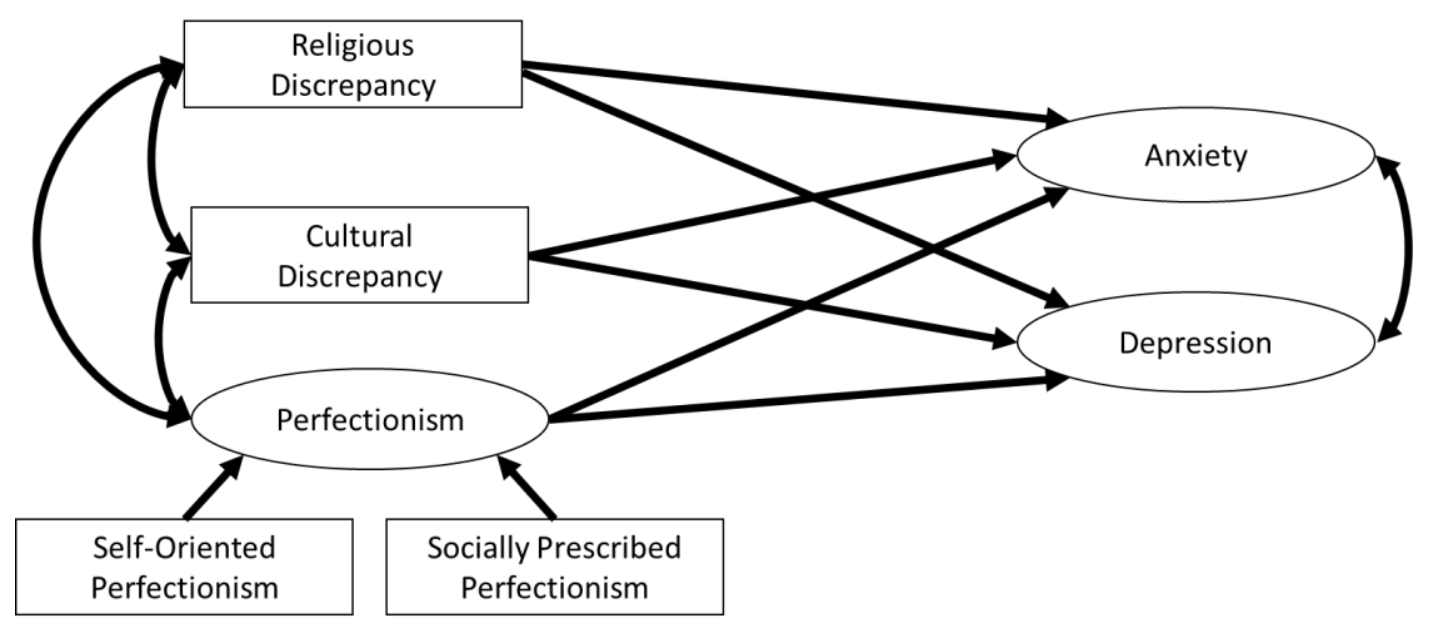


Figure 2.

Model of Jewish Self-Discrepancies on Spiritual Well-Being.

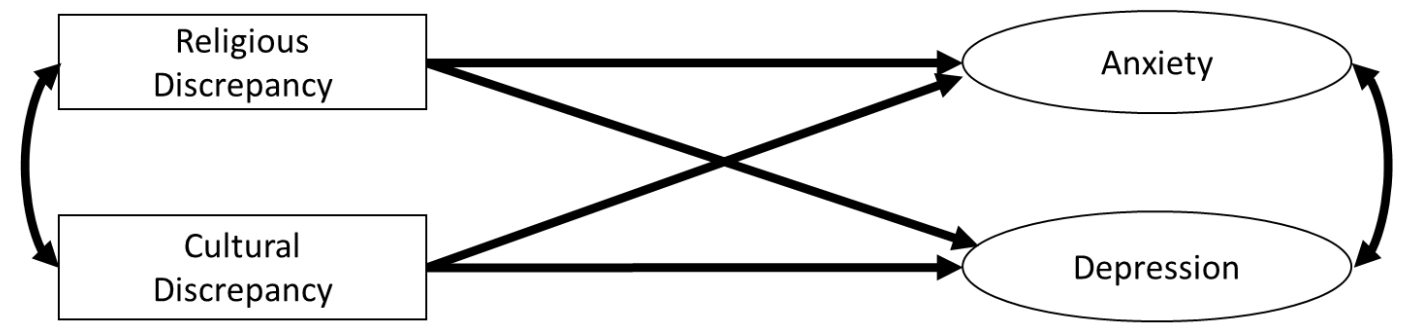


Figure 3

Results of Ideal Jewish Self-Discrepancies on Mental Well-Being

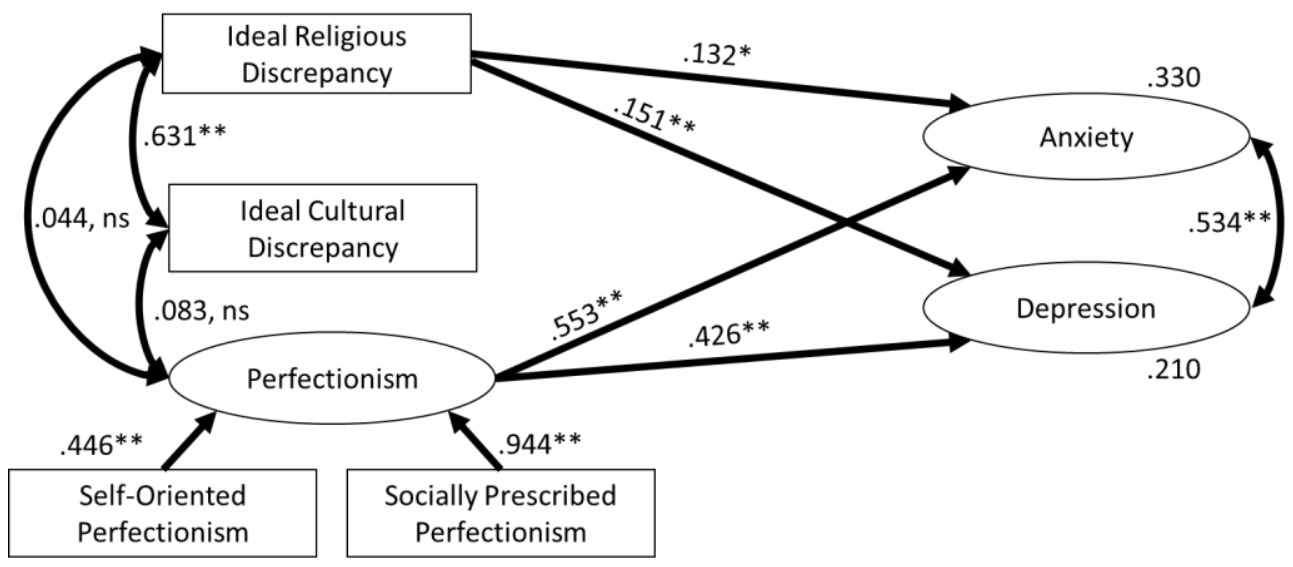


Figure 4

Results of Ought Jewish Self-Discrepancies on Mental Well-Being

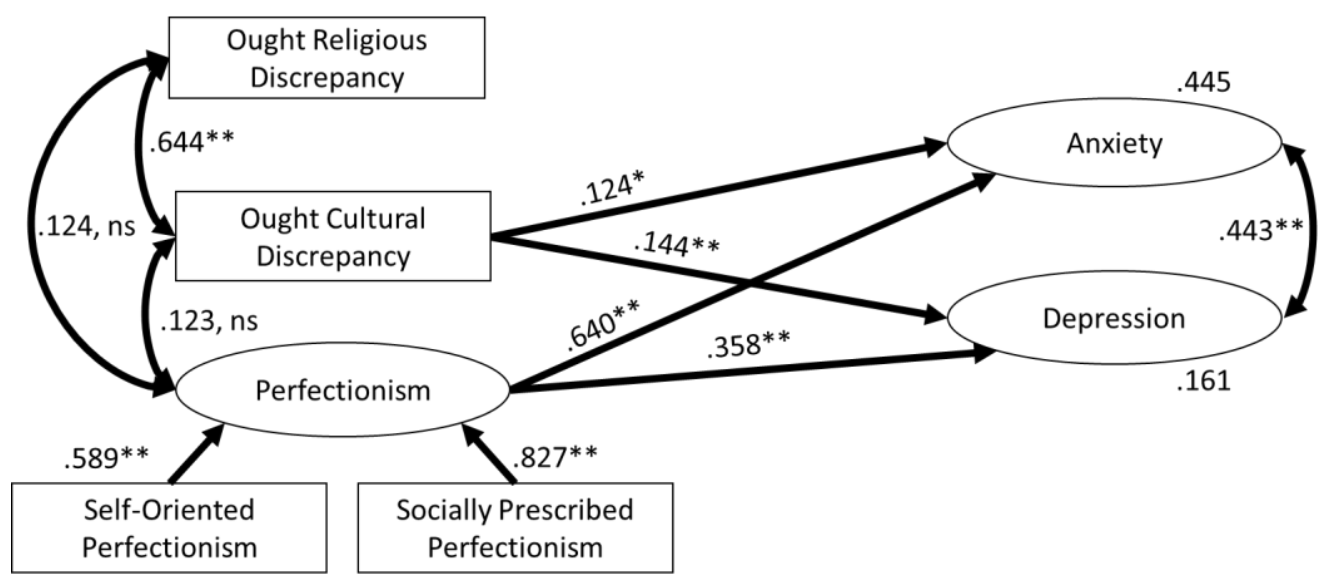


Figure 5

Results of Ideal Jewish Self-Discrepancies on Spiritual Well-Being

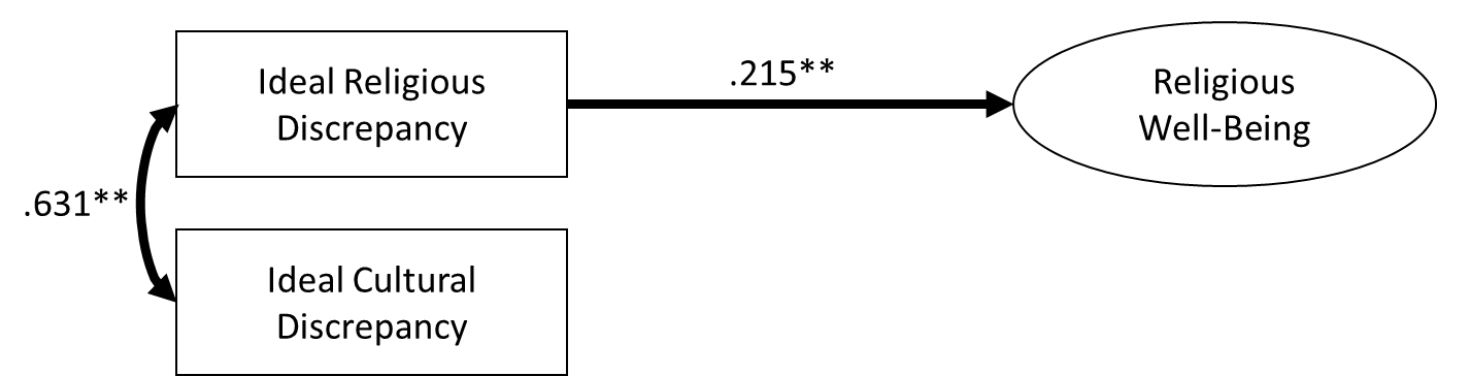


Figure 6

Results of Ought Jewish Self-Discrepancies on Spiritual Well-Being

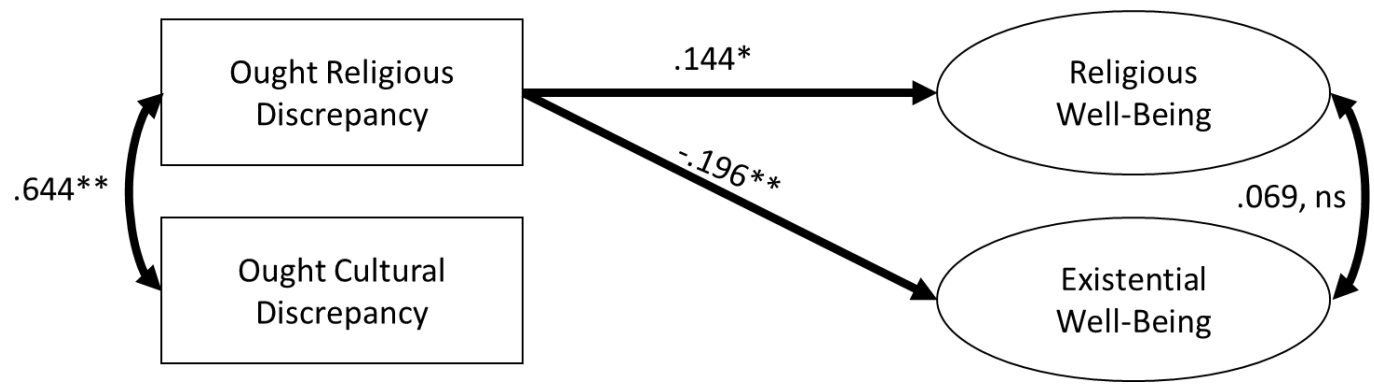


Figure 7

Interaction of A-I Religious Discrepancy and MSE on ESWB

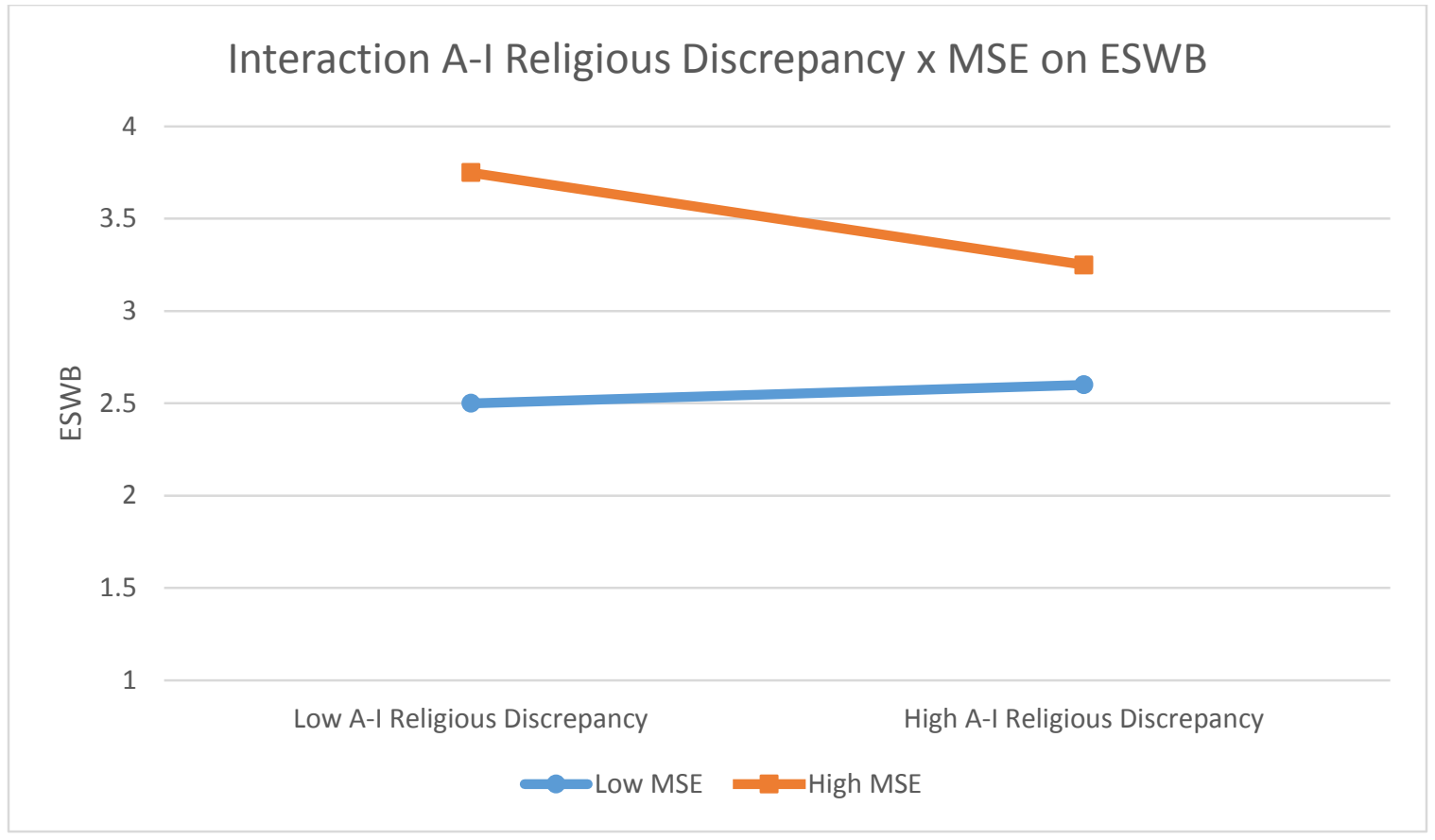


CURRICULUM VITA

Jason R. Goldstein

\title{
Contact Information
}

\author{
882 E Glenn St., Unit \#2 \\ Tucson, AZ 85719 \\ (561) 762-0348 \\ jason.goldstein05@gmail.com
}

\section{Education Information}

Ph.D. Counseling Psychology (APA Accredited), August 2015

University of Louisville, Louisville, Kentucky

Dissertation: The Role of Self-Discrepancies in American Jewish Identities on Mental and Spiritual Well-Being

Defended: July 17, 2015.

APA Accredited Pre-Doctoral Internship, July 2014-July 2015

Southern Arizona Psychology Internship Center

La Frontera, Inc., Tucson, AZ

M.Ed. $\quad$ Master of Education, Counseling Psychology, August 2012

University of Louisville, Louisville, Kentucky

B.S. Bachelor of Science, Psychology, May 2009

University of Florida, Gainesville, Florida

Minors: Religion, Jewish Studies

\section{Clinical Experience}

Pre-doctoral Intern Southern Arizona Psychology Internship Center

Tucson, Arizona, July 2014-July 2015. Training Director: Dr. Breslin

Counseling Center University of Louisville Counseling Center

Therapist Louisville, KY, July 2013-May 2014. Supervisor: Dr. Kalawski

Research Individual Psychodynamic Client-Feedback Clinical Trial

Therapist University of Louisville, August 2013-May 2014. Supervisor: Dr. Owen

Assessment $\quad$ Cedar Lake Lodge

Therapist LaGrange, KY,Sep. 2013-Aug. 2014. Supervisor: Dr. Hicks

Community Communicare Inc. Community Mental Health

Therapist Radcliff, Kentucky, Sep. 2013-April 2014. Supervisor: Dr. Wendall 
Assessment

Therapist

Community

Therapist

Military

Therapist
Seven Counties Services Community Mental Health

Louisville, Kentucky, May 2012 - Aug. 2012. Supervisor: Dr. Scaccia

$\underline{\text { Seven Counties Services Community Mental Health }}$

Louisville, Kentucky, May 2011-May 2012. Supervisor: Dr. Jackson

Fort Knox Department of Behavioral Health

Fort Knox, Kentucky, May 2010-April 2011. Supervisor: Dr. Thomas

\section{Teaching Experiences}

Learning Theory, Human Growth and Development (Graduate level course)

University of Louisville, July 2012-July 2013

Learning Theory, Human Growth and Development (Undergraduate level course)

University of Louisville, August 2011-May 2013

\section{Presentations}

Goldstein, J. (2015, May). Forgiveness: Challenging misperceptions and integrating adaptive views of self and others into therapeutic interventions. Presentation provided for La Frontera, Inc and community clinicians, Tucson, AZ

Goldstein, J. (2015, May). Introduction to Cognitive Processing Therapy. Presentation provided for La Frontera, Inc. and community clinicians, Tucson, AZ

Goldstein, J. \& Leach, M.M. (2010, August). Self-forgiveness and self-condemnation among Christians and Jews. Poster presentation at the 118th Annual Convention of the American Psychological Association, San Diego, CA.

Goldstein, J. (2014, November). Affect phobia: Short-term Dynamic Psychotherapy and Trauma-Informed Care. Minor presentation provided for Southern Arizona Psychology Internship Center, Tucson, AZ.

\section{Professional Activities}

Doctoral Student Organization: President and Student Representative

University of Louisville Department of Counseling Psychology, May 2010-May 2012

Diversity Committee: Member and Student Representative

University of Louisville Department of Counseling Psychology, Aug 2011-May 2014

APA for Graduate Students: Campus Representative

University of Louisville Department of Counseling Psychology, Aug 2009-Aug 2010 


\section{Research Experience}

Research Assistant Relationship and Psychotherapy Lab

University of Louisville, Aug. 2013-May 2014. Supervisor: Dr. Owen

Research Assistant Department of Educational and Counseling Psychology

University of Louisville, Aug. 2009-May 2014. Supervisor: Dr. Leach

Research Assistant Impression Management Lab

University of Florida, Aug. 2007-May 2008. Supervisor: Dr. Schlenker

\section{Professional Trainings and Seminars}

Cognitive Processing Therapy Workshop: Center for Deployment Psychology

Preventing PTSD after Trauma and Cultural Considerations for African Americans

The Effects of PTSD on Family Members of Military and Veteran Services Members

Exploring New Perspectives on Psychological Trauma

Asking the Hard Questions: Assessment and Management of Suicidal Behaviors in Clinical

Settings

Suicide Assessment and Client De-escalation Training

The Skinny on Client Feedback: Using Client Feedback to Improve Outcome and Empower Clients

Asking the Right Questions and Accessing the Best Research: Evidence-based Practice

Early Contemporary Psychodynamic Psychotherapy: An Evidence-based Approach

Emotion Focused Couples Therapy One Day Intensive Training

Couples Therapy Workshop: Introduction to Concepts and Skills

An Introduction to Parent-Child Interaction Therapy

Rorschach Performance Assessment System (R-PAS): Introduction and Clinical Utility

HIV and Stigma: An Informed Conversation

Object Relations Therapy: Introduction to Key Concepts and Application in Clinical Settings

Childhood Sensory Integration, Mental Health Assessment, and Diagnosis

\section{Outreach Participation}

Out of the Darkness Walk and Recovery Expo: Assisted in depression screenings and suicide prevention

Take Back the Night to raise awareness of sexual violence and advocate for violence prevention

Mental Health Awareness and Screening Day

Volunteer activities and fundraisers for Brooklawn Child and Family Services

Consultation project to for University of Louisville Department of Counseling Psychology to inform the development of program-affiliated community-based mental health clinic. 